\title{
DEMATEL Technique: A Systematic Review of the State-of-the-Art Literature on Methodologies and Applications
}

\author{
Sheng-Li Si, ${ }^{1}$ Xiao-Yue You, ${ }^{1,2}$ Hu-Chen Liu ${ }^{D},{ }^{3}$ and Ping Zhang ${ }^{1,3}$ \\ ${ }^{1}$ School of Economics and Management, Tongji University, Shanghai 200092, China \\ ${ }^{2}$ Institute for Manufacturing, University of Cambridge, Cambridge CB3 OFS, UK \\ ${ }^{3}$ School of Management, Shanghai University, Shanghai 200444, China \\ Correspondence should be addressed to Hu-Chen Liu; huchenliu@shu.edu.cn
}

Received 8 October 2017; Accepted 14 December 2017; Published 14 January 2018

Academic Editor: Marco Pizzarelli

Copyright (C) 2018 Sheng-Li Si et al. This is an open access article distributed under the Creative Commons Attribution License, which permits unrestricted use, distribution, and reproduction in any medium, provided the original work is properly cited.

\begin{abstract}
Decision making trial and evaluation laboratory (DEMATEL) is considered as an effective method for the identification of causeeffect chain components of a complex system. It deals with evaluating interdependent relationships among factors and finding the critical ones through a visual structural model. Over the recent decade, a large number of studies have been done on the application of DEMATEL and many different variants have been put forward in the literature. The objective of this study is to review systematically the methodologies and applications of the DEMATEL technique. We reviewed a total of 346 papers published from 2006 to 2016 in the international journals. According to the approaches used, these publications are grouped into five categories: classical DEMATEL, fuzzy DEMATEL, grey DEMATEL, analytical network process- (ANP-) DEMATEL, and other DEMATEL. All papers with respect to each category are summarized and analyzed, pointing out their implementing procedures, real applications, and crucial findings. This systematic and comprehensive review holds valuable insights for researchers and practitioners into using the DEMATEL in terms of indicating current research trends and potential directions for further research.
\end{abstract}

\section{Introduction}

Decision making trial and evaluation laboratory (DEMATEL) technique was first developed by the Geneva Research Centre of the Battelle Memorial Institute to visualize the structure of complicated causal relationships through matrixes or digraphs [1]. As a kind of structural modeling approach, it is especially useful in analyzing the cause and effect relationships among components of a system. The DEMATEL can confirm interdependence among factors and aid in the development of a map to reflect relative relationships within them and can be used for investigating and solving complicated and intertwined problems. This method not only converts the interdependency relationships into a cause and effect group via matrixes but also finds the critical factors of a complex structure system with the help of an impact relation diagram.

Due to its advantages and capabilities, the approach of DEMATEL has received a great deal of attention in the past decade and many researchers have applied it for solving complicated system problems in various areas. In addition, the DEMATEL has been extended for better decision making under different environments since many real-world systems include imprecise and uncertain information. However, to the best of our knowledge, no systematic review has been performed for the DEMATEL technique and its applications. Therefore, in this study, we present a comprehensive review of the state-of-the-art literature regarding the approaches to decision making based on the DEMATEL. As a result of search using the Scopus database and following a methodological decision analysis, a total of 346 papers published in scientific journals from 2006 to 2016 were reviewed in detail. Based on the selected articles, the main objectives of this review are as follows: (1) to summarize the DEMATEL methods that have been used in the academic literature, (2) to reveal the different usage and application areas of these approaches, (3) to show the current research trends in this field of study, and (4) to find out the potential research directions in the future. 
The remaining part of this paper is structured as follows: In Section 2, we introduce the research methodology used to identify and refine the literature in this study. In Section 3, detailed reviews of each category of the DEMATEL studies are presented. Section 4 describes some general observations and findings based on statistical analysis results of the review. Finally, this paper concludes in Section 5 by summarizing the results and discussing opportunities for future research.

\section{Research Methodology}

For the purpose of this literature review, we searched for articles in the Scopus database published between 2006 and 2016. The choice of this time period is based on the fact that the majority of papers on this topic were published during this period and there are only five articles recorded in the Scopus prior to 2006. Inspired by the Preferred Reporting Items for Systematic Reviews and Meta-Analyses (PRISRMA) method [2, 3], the selection of articles in this study is consisted of three stages, that is, literature search, articles eligibility, and data extraction and summarizing. First, the keyword "DEMATEL" was used for searching in "abstract, title, and keywords" for journal papers, and a total of 509 document results were identified from Scopus. Next, we chose the articles which had used the DEMATEL technique or its extensions to solve real-world problems, and 346 academic papers fell under the scope of this review after title, abstract, and full-text screening. Since this study focuses on both the DEMATEL and its applications, those studies which only modify the DEMATEL technique without applying to actual settings have been eliminated (for the interested readers, please refer, e.g., to [4-6]). Finally, the resulting papers were reviewed thoroughly to identify the focus, method, application, and combination with other methods. Also articles were summarized based on various criteria such as year of publication, application areas, and citations.

Based on the DEMATEL methods adopted, the selected publications are roughly grouped into five categories: the ones using classical DEMATEL (105 articles), the ones using fuzzy DEMATEL (63 articles), the ones using grey DEMATEL (12 articles), the ones combining analytical network process (ANP) and DEMATEL (154 articles), and the ones based on other DEMATEL methods (12 articles). The classification scheme of the DEMATEL articles is shown in Figure 1. Most of the papers on ANP and DEMATEL hybridization are included in a review paper of DEMATEL approaches for criteria interaction handling with ANP by Gölcük and Baykasoğlu [7]. Therefore, in the following sections, we will not discuss the studies which apply the DEMATEL in conjunction with ANP to deal with interactions among criteria.

\section{Reviews of DEMATEL Methods}

3.1. The Classical DEMATEL. As stated earlier, the DEMATEL technique can convert the interrelations between factors

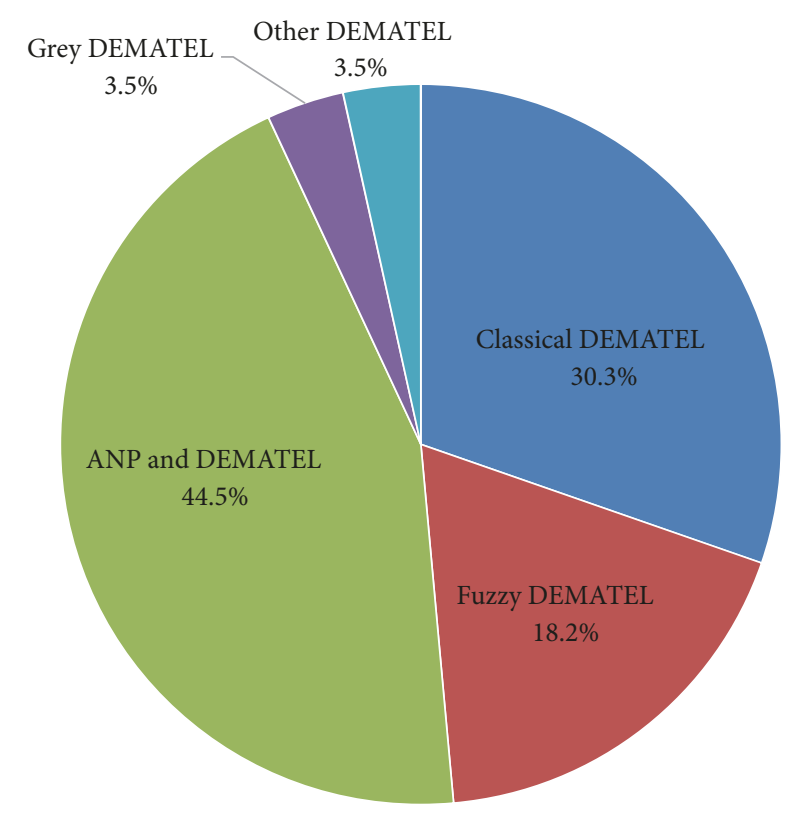

FIGURE 1: Classification scheme of the DEMATEL articles.

into an intelligible structural model of the system and divide them into a cause group and an effect group [8]. Hence, it is an applicable and useful tool to analyze the interdependent relationships among factors in a complex system and rank them for long-term strategic decision making and indicating improvement scopes. The formulating steps of the classical DEMATEL can be summarized as follows [8-10].

Step 1 (generate the group direct-influence matrix $Z$ ). To assess the relationships between $n$ factors $F=\left\{F_{1}, F_{2}, \ldots, F_{n}\right\}$ in a system, suppose that $l$ experts in a decision group $E=$ $\left\{E_{1}, E_{2}, \ldots, E_{l}\right\}$ are asked to indicate the direct influence that factor $F_{i}$ has on factor $F_{j}$, using an integer scale of "no influence (0)," "low influence (1)," "medium influence (2)," "high influence (3)," and "very high influence (4)." Then, the individual direct-influence matrix $Z_{k}=\left[z_{i j}^{k}\right]_{n \times n}$ provided by the $k$ th expert can be formed, where all principal diagonal elements are equal to zero and $z_{i j}^{k}$ represents the judgment of decision maker $E_{k}$ on the degree to which factor $F_{i}$ affects factor $F_{j}$. By aggregating the $l$ experts' opinions, the group direct-influence matrix $Z=\left[z_{i j}\right]_{n \times n}$ can be obtained by

$$
z_{i j}=\frac{1}{l} \sum_{k=1}^{l} z_{i j}^{k}, \quad i, j=1,2, \ldots, n .
$$

Step 2 (establish the normalized direct-influence matrix $X$ ). When the group direct-influence matrix $Z$ is acquired, the normalized direct-influence matrix $X=\left[x_{i j}\right]_{n \times n}$ can be achieved by using

$$
\begin{aligned}
X & =\frac{Z}{s}, \\
s & =\max \left(\max _{1 \leq i \leq n} \sum_{j=1}^{n} z_{i j}, \max _{1 \leq i \leq n} \sum_{i=1}^{n} z_{i j}\right) .
\end{aligned}
$$


All elements in the matrix $X$ are complying with $0 \leq x_{i j}<$ $1,0 \leq \sum_{j=1}^{n} x_{i j} \leq 1$, and at least one $i$ such that $\sum_{j=1}^{n} z_{i j} \leq s$.

Step 3 (construct the total-influence matrix $T$ ). Using the normalized direct-influence matrix $X$, the total-influence matrix $T=\left[t_{i j}\right]_{n \times n}$ is then computed by summing the direct effects and all of the indirect effects by

$$
\begin{array}{r}
T=X+X^{2}+X^{3}+\cdots+X^{h}=X(I-X)^{-1}, \\
\text { when } h \longrightarrow \infty,
\end{array}
$$

in which $I$ is denoted as an identity matrix.

Step 4 (produce the influential relation map (IRM)). At this step, the vectors $R$ and $C$, representing the sum of the rows and the sum of the columns from the total-influence matrix $T$, are defined by the following formulas:

$$
\begin{aligned}
& R=\left[r_{i}\right]_{n \times 1}=\left[\sum_{j=1}^{n} t_{i j}\right]_{n \times 1}, \\
& C=\left[c_{j}\right]_{1 \times n}=\left[\sum_{i=1}^{n} t_{i j}\right]_{1 \times n}^{T},
\end{aligned}
$$

where $r_{i}$ is the $i$ th row sum in the matrix $T$ and displays the sum of the direct and indirect effects dispatching from factor $F_{i}$ to the other factors. Similarly, $c_{j}$ is the $j$ th column sum in the matrix $T$ and depicts the sum of direct and indirect effects that factor $F_{j}$ is receiving from the other factors.

Let $i=j$ and $i, j \in\{1,2, \ldots, n\}$; the horizontal axis vector $(R+C)$ named "Prominence" illustrates the strength of influences that are given and received of the factor. That is, $(R+C)$ stands for the degree of central role that the factor plays in the system. Alike, the vertical axis vector $(R-C)$ called "Relation" shows the net effect that the factor contributes to the system. If $\left(r_{j}-c_{j}\right)$ is positive, then the factor $F_{j}$ has a net influence on the other factors and can be grouped into cause group; if $\left(r_{j}-c_{j}\right)$ is negative, then the factor $F_{j}$ is being influenced by the other factors on the whole and should be grouped into effect group. Finally, an IRM can be created by mapping the dataset of $(R+C, R-C)$, which provides valuable insights for decision making.

3.1.1. Observations and Findings. Table 1 summarizes all the classical DEMATEL studies based on the particular purpose of using DEMATEL, the topic of decision making, and other methods combined. According to the distinct usage of the DEMATEL method, the current classical DEMATEL researches can be classified into three types: the first type is merely clarifying the interrelationships between factors or criteria; the second type is identifying key factors based on the causal relationships and the degrees of interrelationship between them; the third type is determining criteria weights by analyzing the interrelationships and impact levels of criteria.
In Table 1, we have provided an overview on the existing applications of the classical DEMATEL for solving complicated and intertwined problems in many fields, based on which we now point out some critical steps added to the original approach.

Step 4-1 (set a threshold value to draw the IRM). In the above, the IRM is constructed based on the information from the matrix $T$ to explain the structure relations of factors. But, in some situations, the IRM will be too complex to show the valuable information for decision making if all the relations are considered. Therefore, a threshold value $\theta$ is set in many studies to filter out negligible effects. That is, only the element of matrix $T$, whose influence level is greater than the value of $\theta$, is selected and converted into an IRM.

If the threshold value is too low, many factors are included and the IRM will be too complex to comprehend. In contrast, some important factors may be excluded if the threshold value is too high. In the literature, the threshold value $\theta$ is usually determined by experts through discussions $[10,11]$, the results of literature review, the brainstorming technique [12], the maximum mean deentropy (MMDE) [13], the average of all elements in the matrix $T$ [14], or the maximum value of the diagonal elements of the matrix $T$ [15].

Step 4-2 (obtain the inner dependence matrix $T^{\prime}$ ). When the total-influence matrix $T$ is produced, in $[16,17]$, an inner dependence matrix $T^{\prime}$ is acquired by normalizing the matrix $T$ so that each column sum is equal to 1 . But, in [18], the inner dependence matrix $T^{\prime}$ is derived based on the threshold value $\theta$ and only the factors whose effects in the matrix $T$ are larger than $\theta$ are shown in the matrix $T^{\prime}$.

To interpret the results easily and keep the complexity of the system manageable, Tzeng [19] established a simplified normalized total-influence matrix $\widehat{T}^{s}$ using a normalization method and the threshold value $\theta$. First, the normalized totalinfluence matrix $\widehat{T}=\left[\widehat{t}_{i j}\right]_{n \times n}$ is calculated by using (6) to force the values of the matrix $T$ within the scope of a measurement scale.

$$
\widehat{t}_{i j}=\frac{(k-0)\left(t_{i j}-\min t_{i j}\right)}{\max t_{i j}-\min t_{i j}},
$$

where $k$ is the highest score for measuring the degree of relative impact between factors and $k=4$ if the integral scale of 0 to 4 is used. Then, the simplified normalized totalinfluence matrix $\widehat{T}^{s}=\left[\widehat{t}_{i j}^{s}\right]_{n \times n}$ is obtained by eliminating insignificant effects in the matrix $\widehat{T}$ based on the threshold value $\theta$. That is,

$$
\widehat{t}_{i j}^{s}= \begin{cases}\widehat{t}_{i j} & \text { if } \widehat{t}_{i j}>\theta \\ 0 & \text { if } \widehat{t}_{i j} \leq \theta\end{cases}
$$

Step 4-2' (divide the IRM into four quadrants). Once an IRM is acquired, eight of the classical DEMATEL studies classified the factors in a complicated system into four quadrants according to their locations in the diagram. In [20-22], the IRM is divided into four quadrants I to IV, as displayed in 


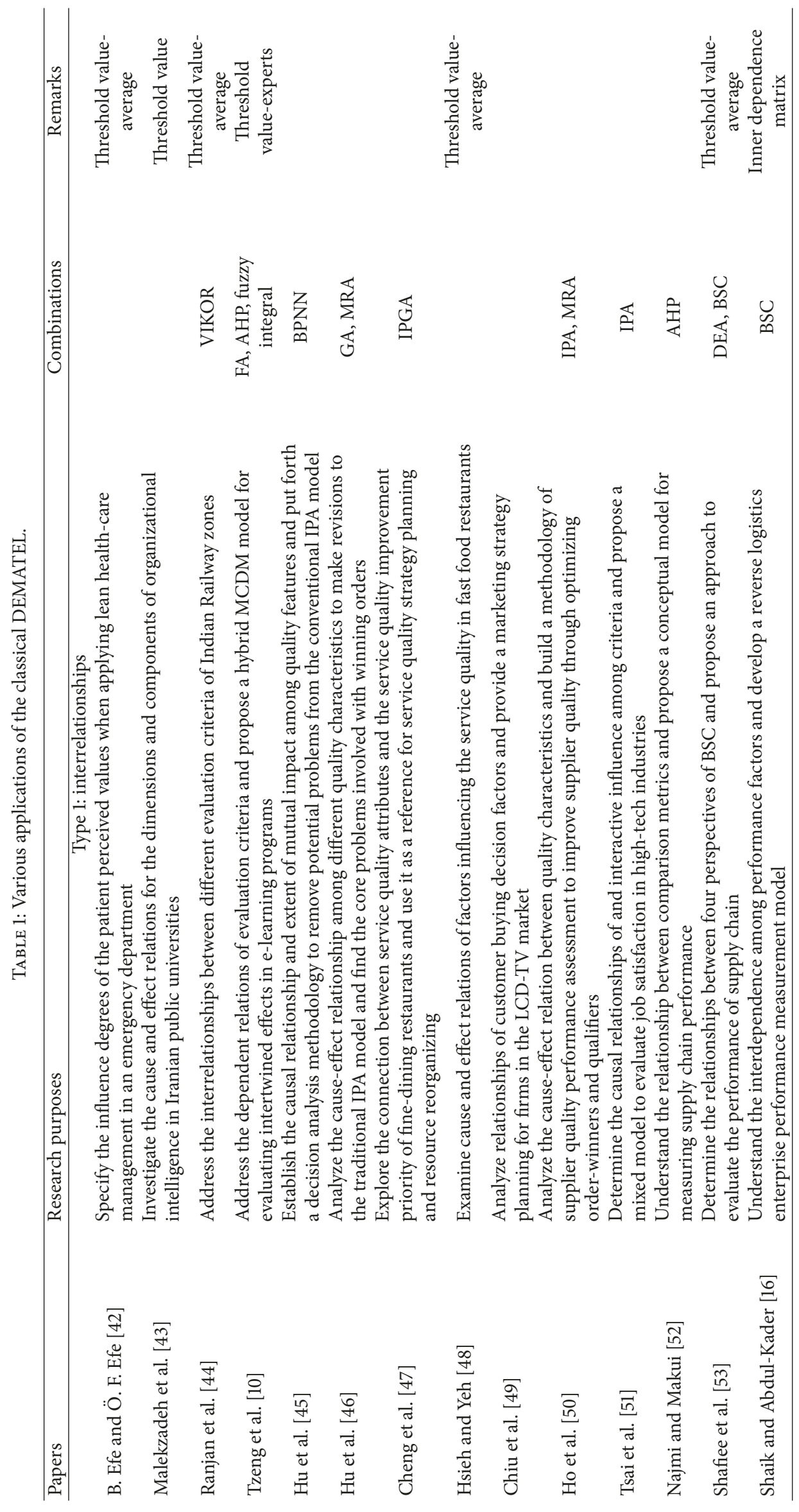




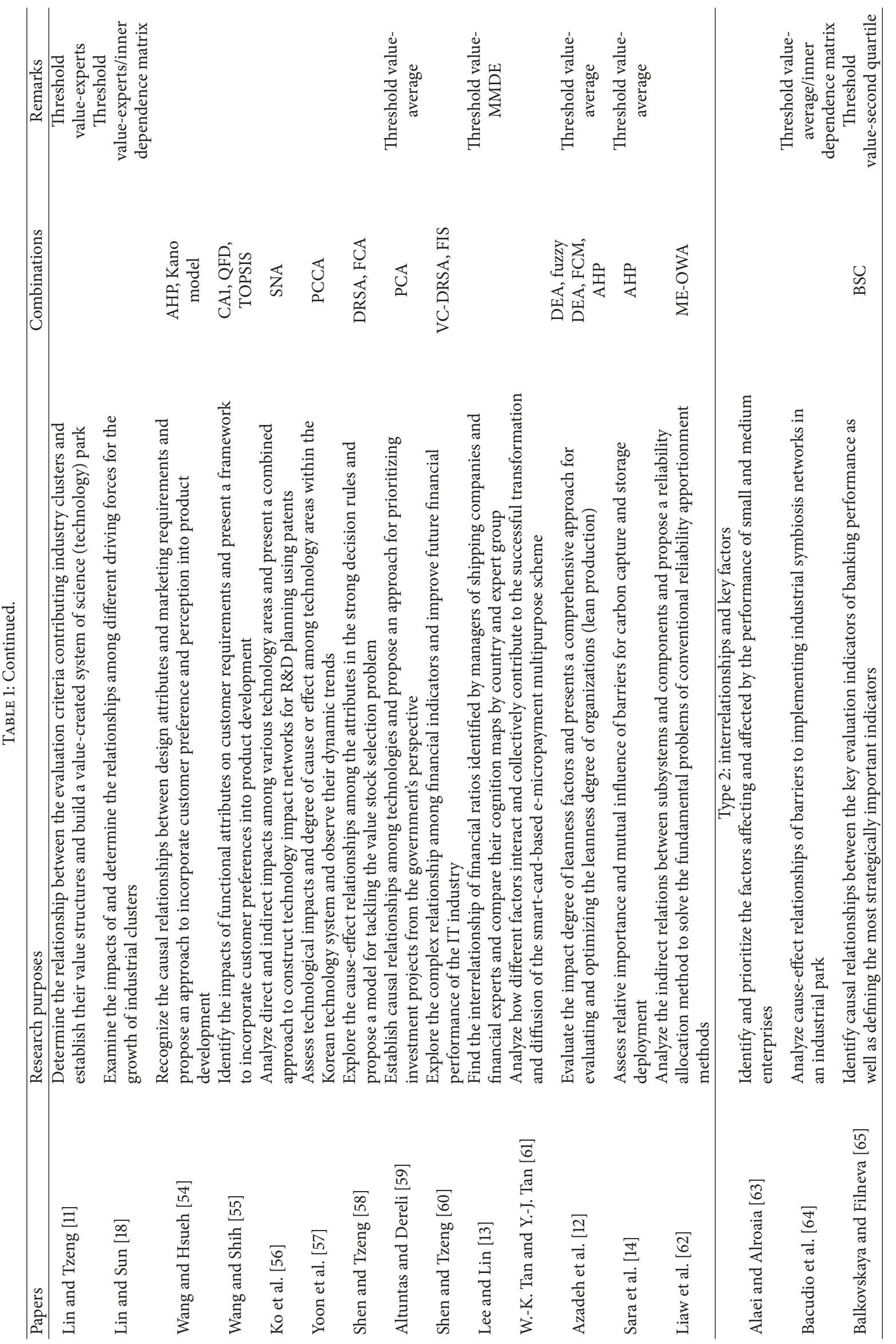




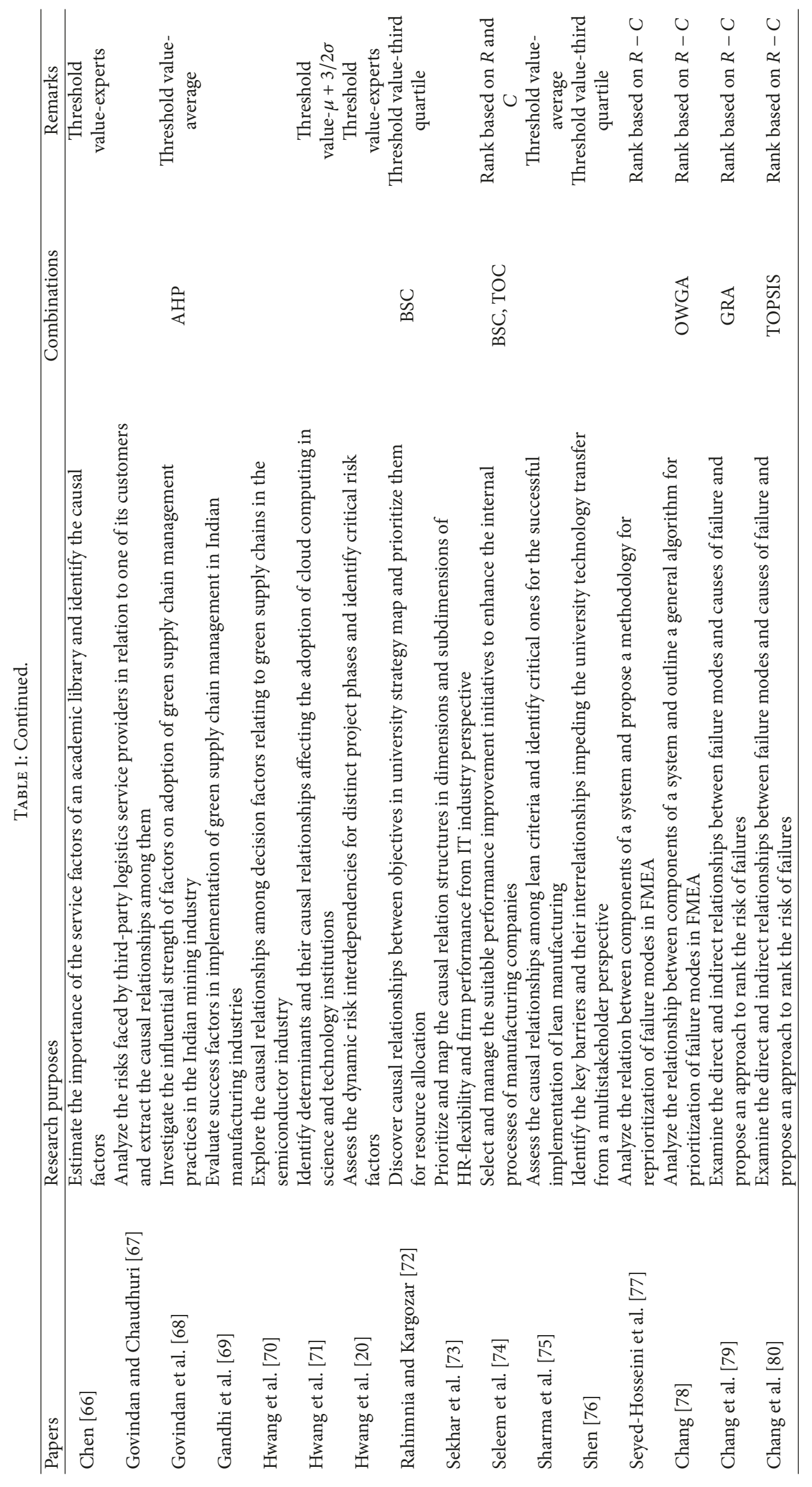




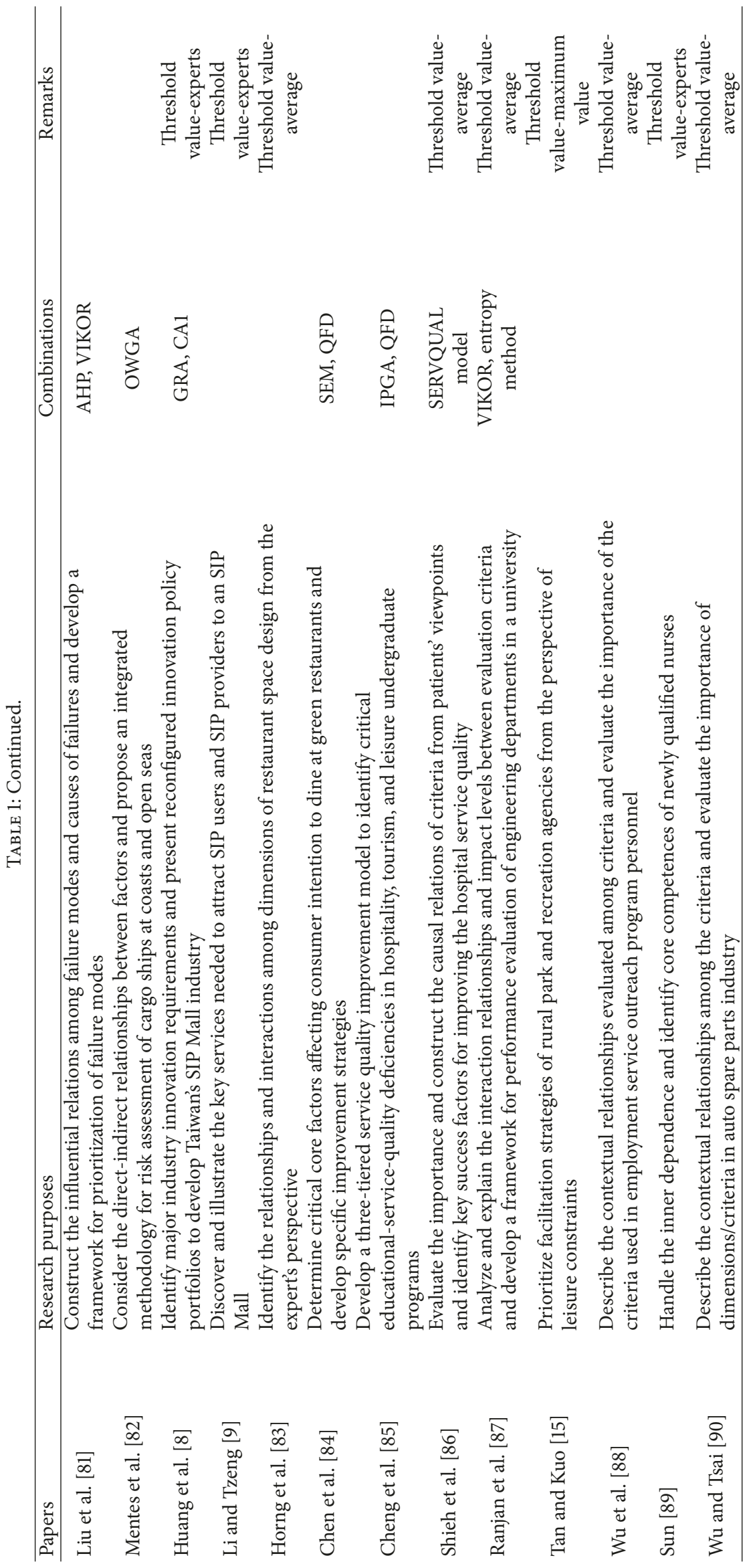




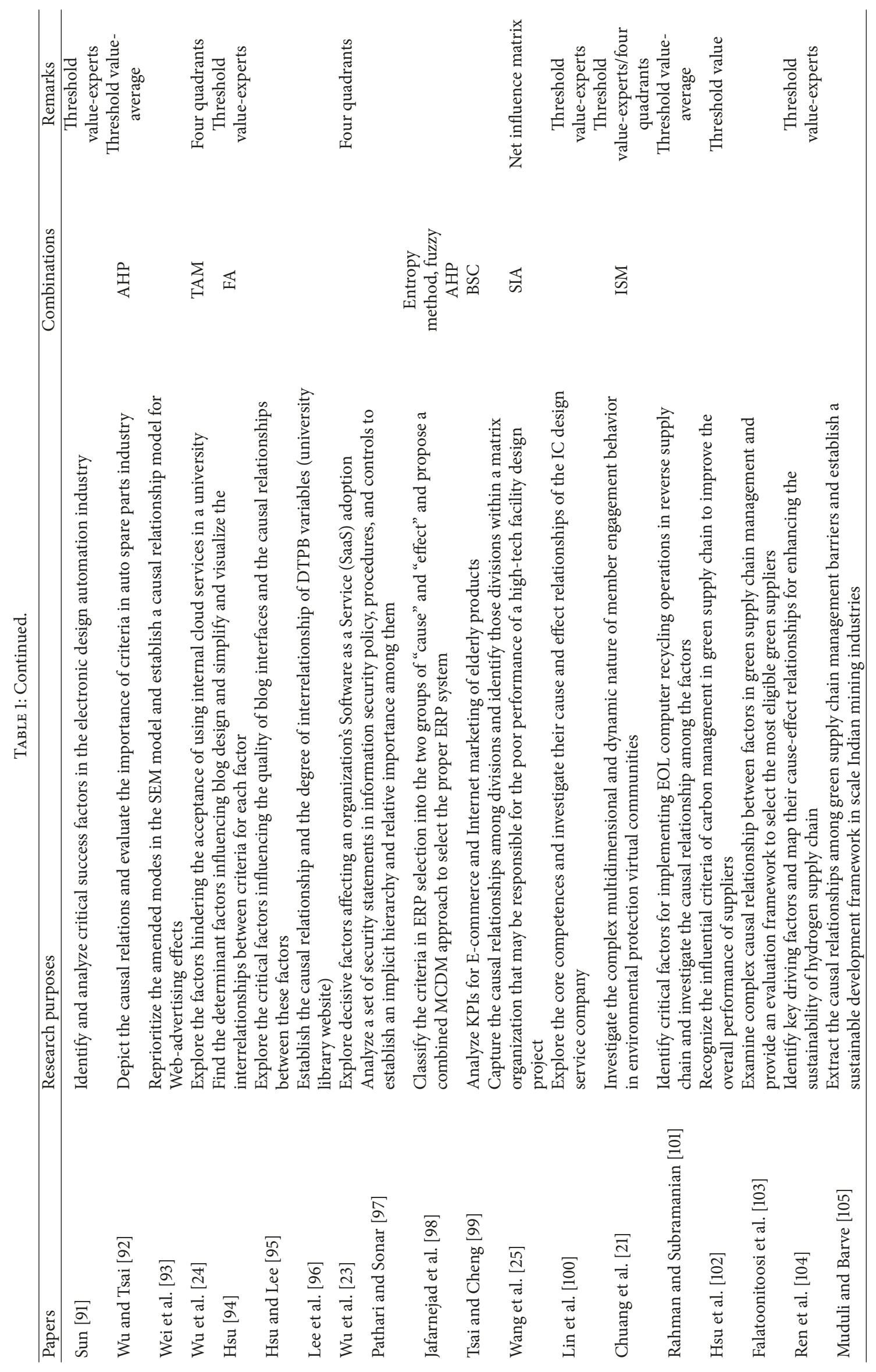




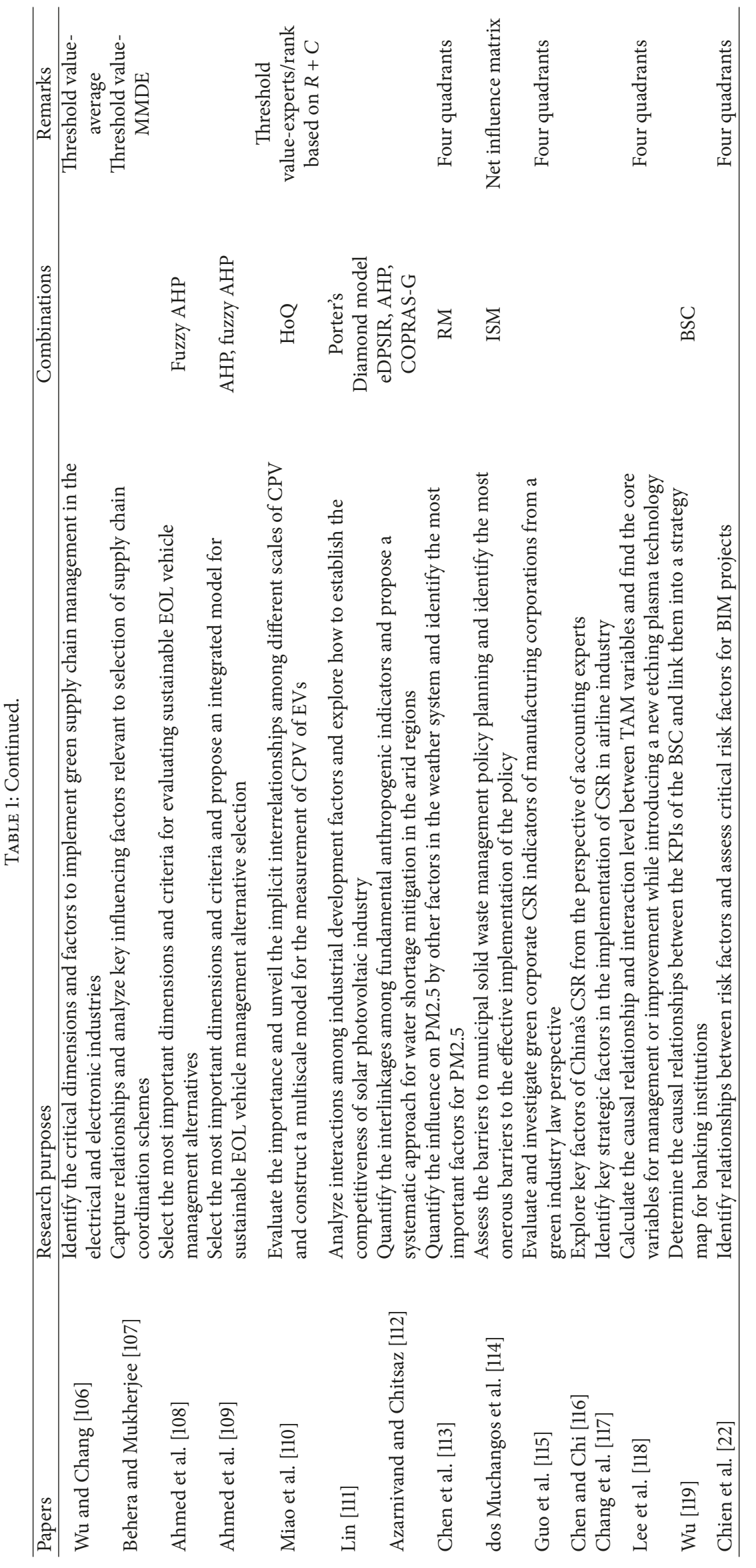




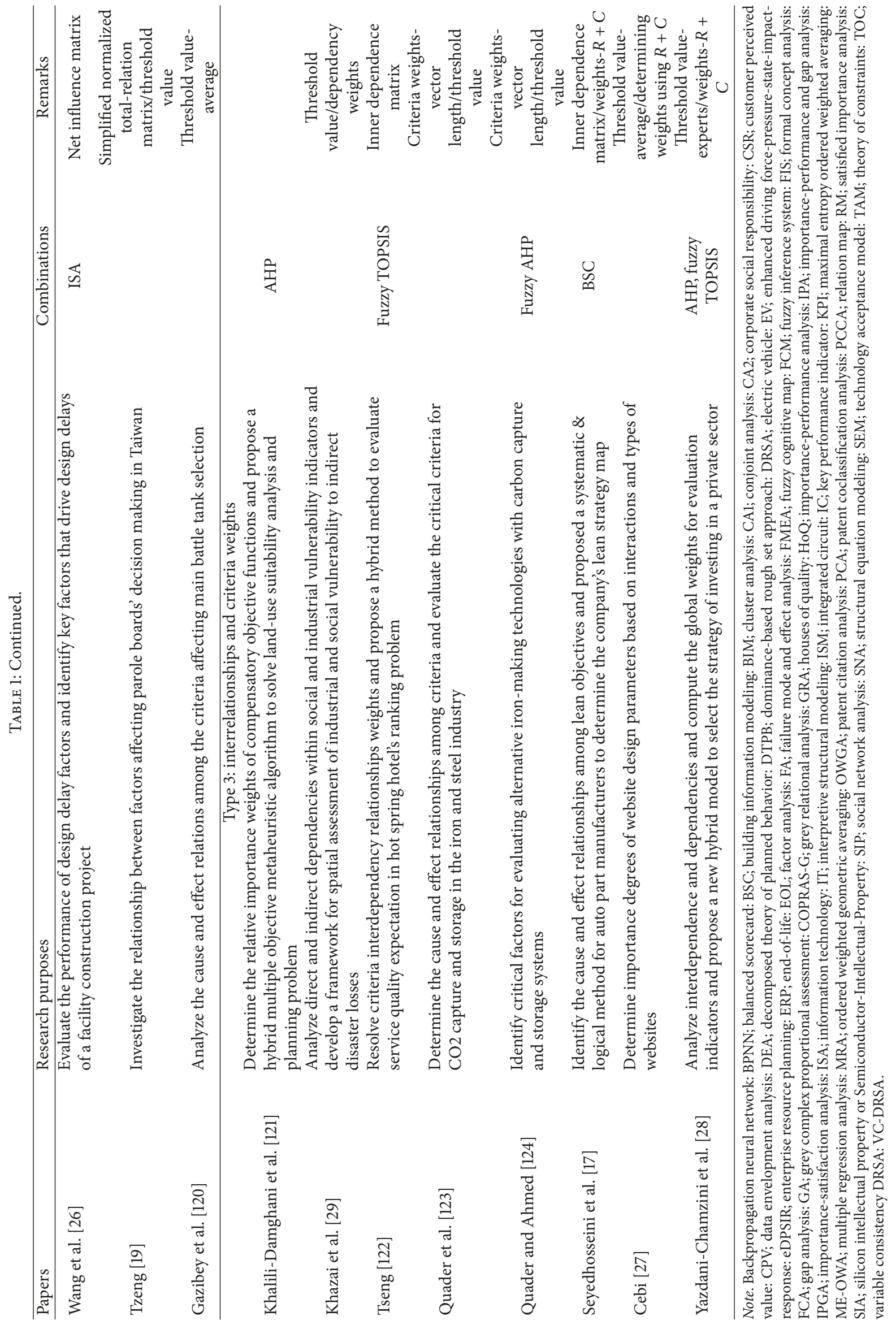




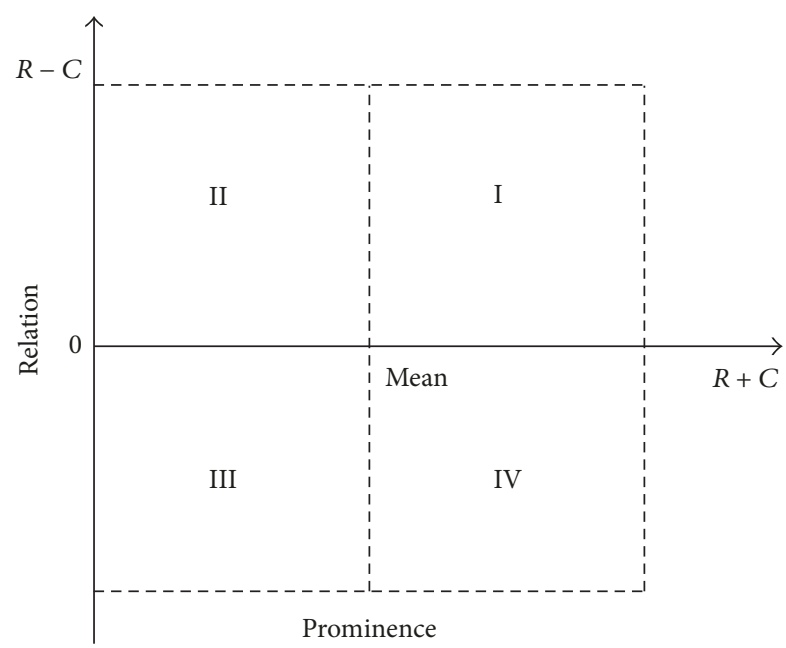

FIGURE 2: Four-quadrant IRM.

Figure 2, by calculating the mean of $(R+C)$. The factors in quadrant I are identified as core factors or intertwined givers since they have high prominence and relation; the factors in quadrant II are identified as driving factors or autonomous givers because they have low prominence but high relation. The factors in quadrant III have low prominence and relation and are relatively disconnected from the system (called independent factors or autonomous receivers); the factors in quadrant IV have high prominence but low relation (called impact factors or intertwined receivers), which are impacted by other factors and cannot be directly improved. From Figure 2, decision makers can visually detect the complex causal relationships among factors and further spotlight valuable insights for decision making.

In addition, $\mathrm{Wu}$ et al. [23] developed a duo-theme DEMATEL to explore the decisive factors affecting the adoption Software as a Service (SaaS) in an organization. They treated the perceived benefits $(\mathrm{PB})$ and perceived risks (PR) of adopting SaaS solutions as two distinct themes and developed a four-quadrant causal map, called PB-PR matrix, to facilitate decision making (see Figure 3). The primary difference between the duo-theme and the traditional DEMATEL is that the duo-theme DEMATEL combine two IRMs into a single PB-PR matrix by transforming "positive" $(R+C)$ value of each factor in PR into "negative" [24].

Step 5-1 (net influence matrix). After visualizing the complex causal relationships among factors using the IRM, Wang et al. $[25,26]$ further developed the net influence matrix $N=$ $\left[\mathrm{Net}_{i j}\right]_{n \times n}$ to evaluate the strength of influence of one factor on another, in which

$$
\mathrm{Net}_{i j}=t_{i j}-t_{j i} .
$$

Step 6 (calculate the importance weights for criteria). In some studies, the classical DEMATEL technique was used to compute the weights of criteria. Normally, the criteria weights are determined based on the prominence $(R+C)$ through a normalization procedure as follows $[27,28]$ :

$$
w_{i}=\frac{r_{i}+c_{i}}{\sum_{i=1}^{n} r_{i}+c_{i}}, \quad i=1,2, \ldots, n .
$$

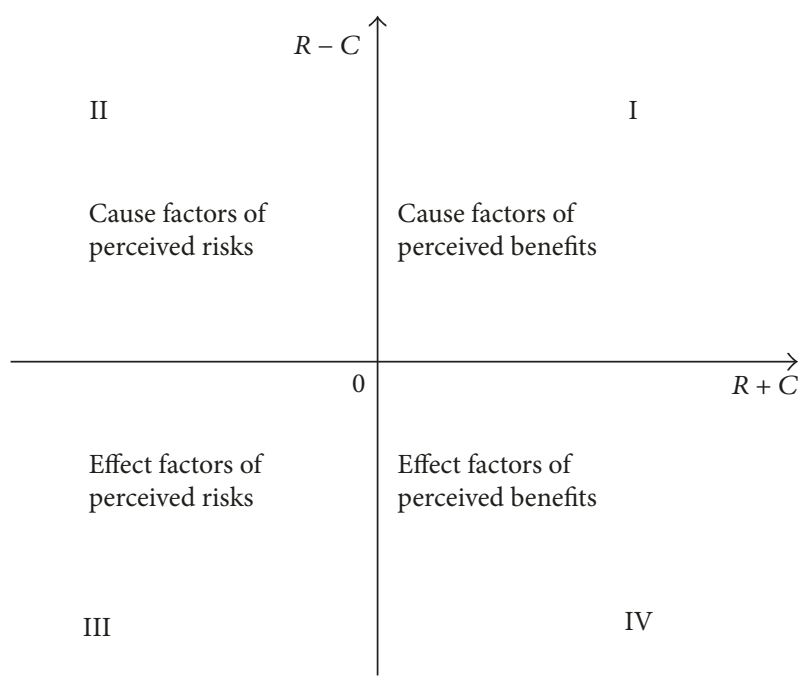

FIGURE 3: The PB-PR matrix.

To correct for structural relations among criteria, Khazai et al. [29] proposed using the degree of dispatching, $r_{i}$, to calculate the dependency weights of criteria:

$$
w_{i}^{d}=1-\frac{r_{i}-r_{\min }}{r_{\max }-r_{\min }},
$$

where $r_{\min }=n\left(\min _{i, j} t_{i j}\right)$ and $r_{\max }=n\left(\max _{i, j} t_{i j}\right)$.

Then, the overall weight of each criterion $w_{i}$ is derived by

$$
\begin{aligned}
& w_{i}=\frac{w_{i}^{o}}{\sum_{i=1}^{n} w_{i}^{o}}, \quad i=1,2, \ldots, n, \\
& w_{i}^{o}=w_{i}^{\mathrm{im}} \times w_{i}^{d},
\end{aligned}
$$

where $w_{i}^{\mathrm{im}}$ is the importance weight of the $i$ th criterion assigned by a group of experts.

3.1.2. Comparison with Other MCDM Methods. In the literature, a lot of effective MCDM methods were developed for dealing with group decision making problems [30-32]. In this part, the DEMATEL technique is compared with some other MCDM methods to show its advantages and disadvantages. We choose the most commonly used methods in MCDM, that is, analytic hierarchical process (AHP), grey relational analysis (GRA), technique for order performance by similarity to ideal solution (TOPSIS), VIKOR (Vise Kriterijumska Optimizacija I Kompromisno Resenje), and ELECTRE (ELimination Et Choix Traduisant la REalité), to compare the procedural basis of these MCDM methods.

In the AHP, a hierarchy considers the distribution of a goal among the elements being compared and judges which element has a greater influence on that goal $[33,34]$. The GRA is an impact evaluation model that measures the degree of similarity or difference between two sequences based on relation grade [35]. The VIKOR method introduces the ranking index based on the particular measure of "closeness" to the ideal solution by using linear normalization [36]. The basic principle of the TOPSIS is that the chosen alternative 
should have the shortest distance from the ideal solution and the farthest distance from the negative-ideal solution [37]. The ELECTRE is a prominent outranking MCDM technique, which selects the best action from a proposed set of ones based on multiattribute utility theory [38]. Compared with these MCDM methods, the DEMATEL technique has the following advantages: (1) It effectively analyzes the mutual influences (both direct and indirect effects) among different factors and understands the complicated cause and effect relationships in the decision making problem. (2) It is able to visualize the interrelationships between factors via an IRM and enable the decision maker to clearly understand which factors have mutual influences on one another. (3) The DEMATEL can be used not only to determine the ranking of alternatives, but also to find out critical evaluation criteria and measure the weights of evaluation criteria. Although the AHP can be applied to rank alternatives and determine criteria weights, it assumes that the criteria are independent and fails to consider their interactions and dependencies. The ANP, an advanced version of the AHP, can deal with the dependence and feedback between criteria; but as indicated in [39-41], the assumption of equal weight for each cluster to obtain a weighted supermatrix in the ANP is not reasonable in practical situations.

On the other hand, in comparison to other MCDM methods, the possible disadvantages of the DEMATEL technique may be the following: (1) It determines the ranking of alternatives based on interdependent relationships among them; but other criteria are not incorporated in the decision making problem. (2) The relative weights of experts are not considered in aggregating personal judgments of experts into group assessments. (3) It cannot take into account the aspiration level of alternatives as in the GRA and VIKOR methods or obtain partial ranking orders of alternatives as in the ELECTRE approach. Therefore, the DEMATEL has been integrated with other MCDM methods to combine their desired properties in the literature. Next, we will discuss the situations in which it is more appropriate to use the DEMATEL method before some other methods.

3.1.3. Combination with Other Methods. Analyzing the data contained in Table 1, we can observe that the crisp DEMATEL has been combined with a variety of other methods or tools to solve the management decision problems effectively, and the methods most frequently integrated with the DEMATEL include AHP, balanced scorecard (BSC), TOPSIS, and quality function deployment (QFD). Generally, the classical DEMATEL are applied to the following circumstances in combination with other methods. First, it can be used to identify the interdependency among dimensions or perspectives. For example, the DEMATEL was applied to determine the interrelationships between four BSC perspectives [16] and to unveil the implicit interrelationships of customer requirements [210]. Second, it can be used to calculate the weights of evaluation criteria. For instance, the DEMATEL was employed to resolve criteria interdependency relationship weights and then the TOPSIS is utilized to evaluate the service quality of hot spring hotels [122]. Third, it can be used to determine critical factors or criteria via analyzing their dependent relations. For example, the DEMATEL method was applied first to select the most important sustainable criteria, and fuzzy AHP is constructed next to rank end-oflife vehicle management alternatives [108].

3.2. Fuzzy DEMATEL. In the original DEMATEL, the relationships of decision factors are assessed by crisp values so as to establish a structural model. However, in many realworld applications, human judgments are often unclear and exact numerical values are inadequate to estimate the vague interdependency relationships between criteria. Hence, the concept of fuzzy sets [214] has been applied to the DEMATEL method by many researchers. The fuzzy DEMATEL papers identified in this literature survey are summarized in Table 2 for the convenience of reading and understanding. This table also gives the classification of such papers based on different purposes of using the fuzzy DEMATEL. Generally, two types of fuzzy DEMATEL model have been put forward in the literature, that is, fuzzy logic and DEMATEL and fuzzy-based DEMATEL, which will be outlined briefly in the following.

3.2.1. Fuzzy Logic and DEMATEL. In this model, fuzzy logic and DEMATEL are combined in a decision model but implemented independently. This model first employs fuzzy sets to handle the experts' vague judgments and assessments on impact levels between factors and converts fuzzy numbers into crisp values for the group direct-influence matrix $Z$ and then performs the classical DEMATEL procedure. Based on the basic definitions and operations of fuzzy sets, the following fuzzy logic and DEMATEL methodology was developed [130-132].

Step 1. Evaluate the mutual influences between factors using fuzzy linguistic scale.

In this step, it is necessary to establish a fuzzy linguistic scale to assess the causal relationships among factors. In order to tackle the vagueness and imprecision in human assessments, the linguistic terms "No, Very Low, Low, High, Very High" expressed in triangular fuzzy numbers can be used for the linguistic variable "influence." As a result, the individual direct-influence fuzzy matrix $\widetilde{Z}_{k}=\left[\widetilde{z}_{i j}^{k}\right]_{n \times n}$ is acquired for each of the respondents $E=\left\{E_{1}, E_{2}, \ldots, E_{l}\right\}$, where $\widetilde{z}_{i j}^{k}=\left(z_{i j 1}^{k}, z_{i j 2}^{k}, z_{i j 3}^{k}\right)$ is the fuzzy assessment of expert $E_{k}$ regarding the influence degree between factors $F_{i}$ and $F_{j}$.

Step 2. Aggregate the assessments of experts and set up the group direct-influence fuzzy matrix $\widetilde{Z}$.

After constructing the individual matrixes $\widetilde{Z}_{k}(k=$ $1,2, \ldots, l)$, we can calculate the group direct-influence fuzzy matrix $\widetilde{Z}=\left[\widetilde{z}_{i j}\right]_{n \times n}$ via aggregating all the experts' judgments, where $\widetilde{z}_{i i}$ can be viewed as a triangular fuzzy number $(0,0,0)$ and $\widetilde{z}_{i j}$ is derived by

$$
\begin{aligned}
\widetilde{z}_{i j} & =\left(z_{i j 1}, z_{i j 2}, z_{i j 3}\right)=\frac{1}{l} \sum_{k=1}^{l} \widetilde{z}_{i j}^{k} \\
& =\left(\frac{1}{l} \sum_{k=1}^{l} z_{i j 1}^{k}, \frac{1}{l} \sum_{k=1}^{l} z_{i j 2}^{k}, \frac{1}{l} \sum_{k=1}^{l} z_{i j 3}^{k}\right) .
\end{aligned}
$$




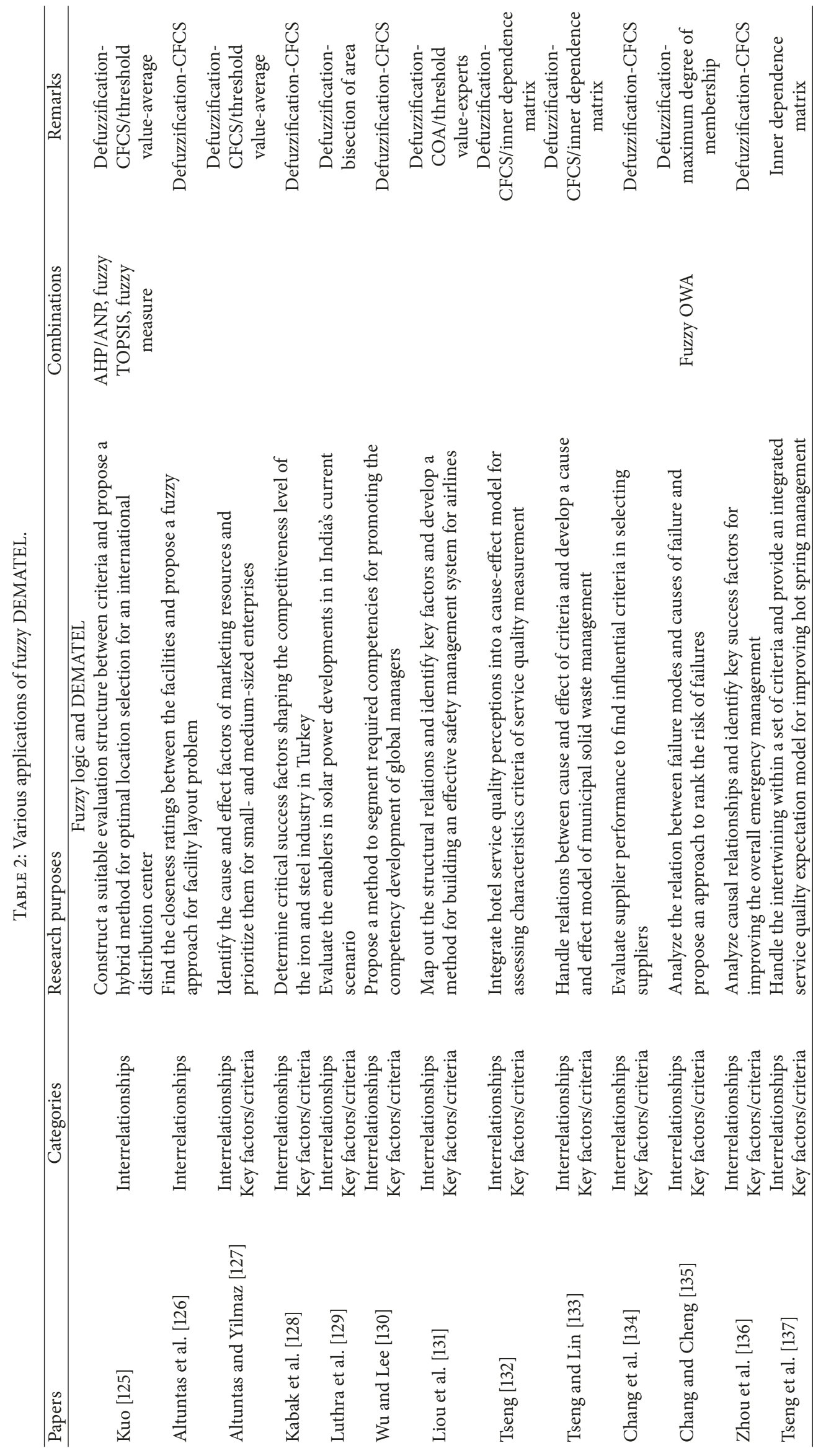




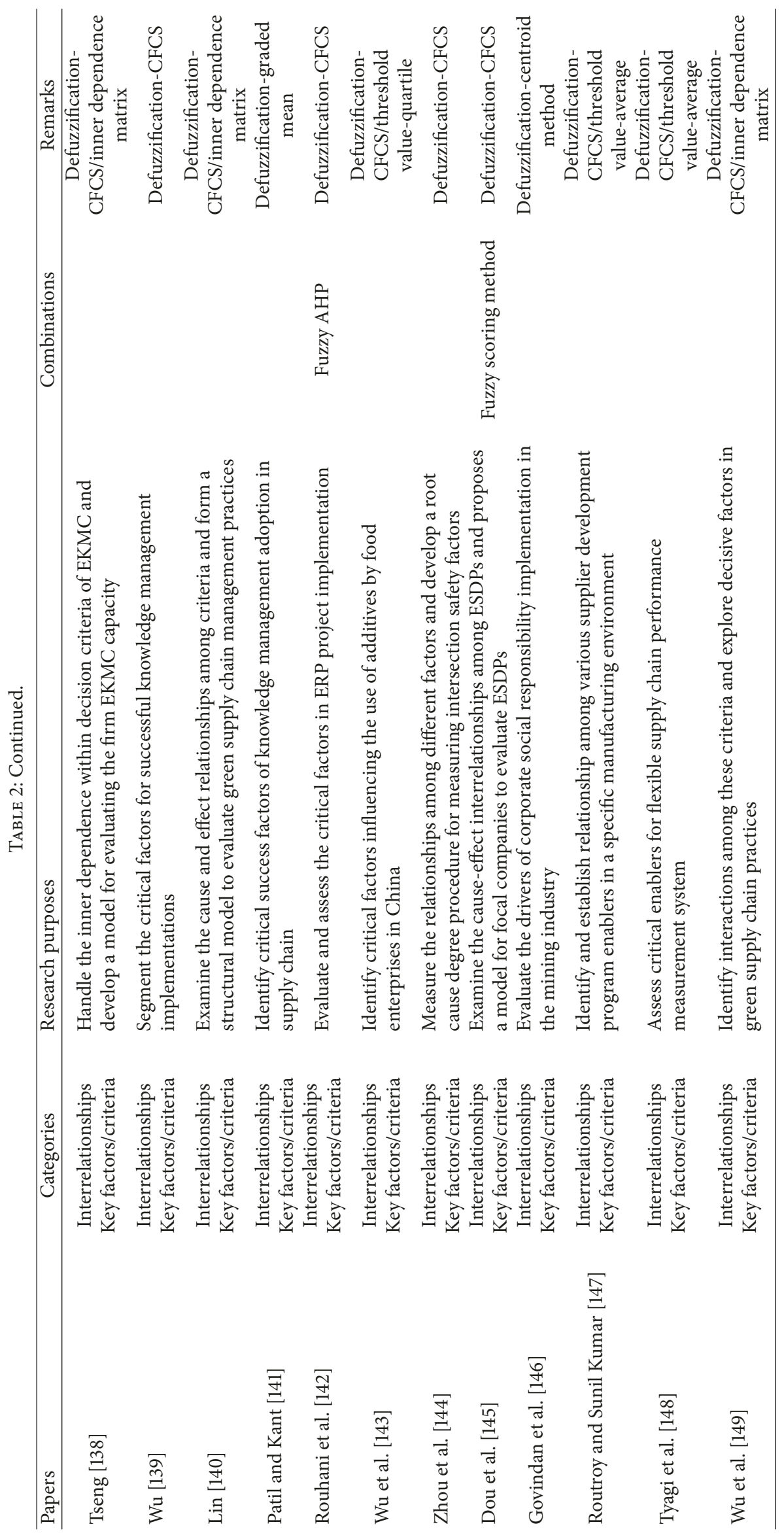




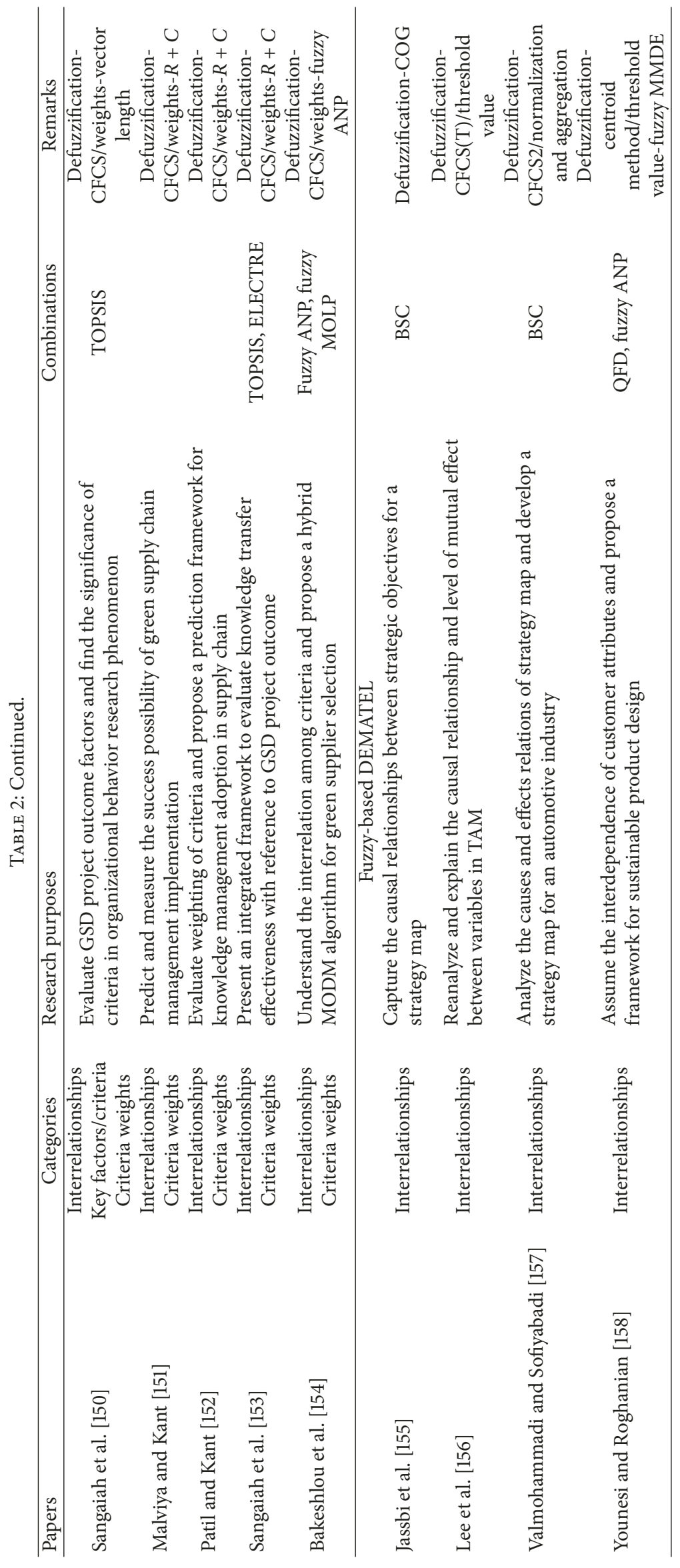




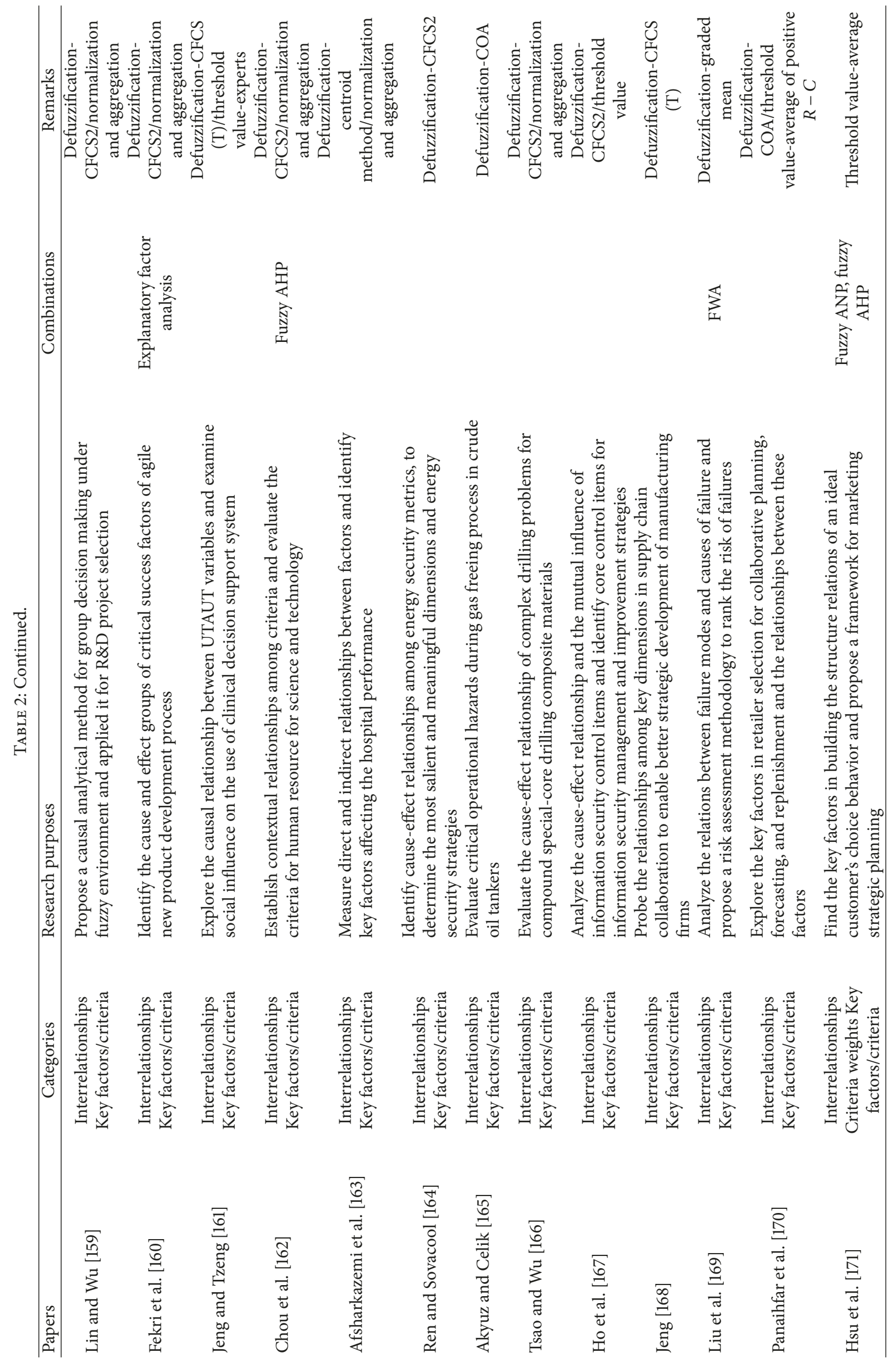




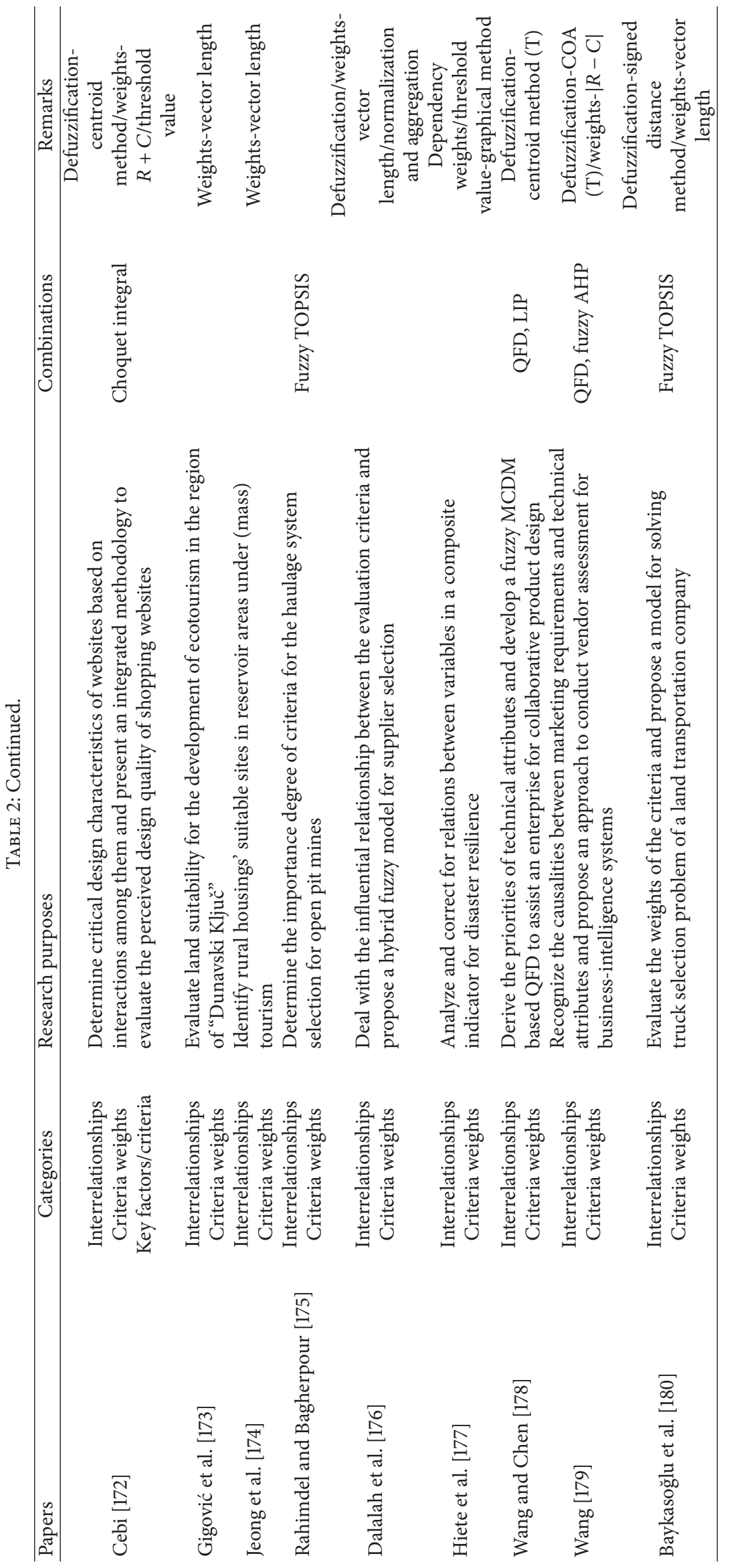




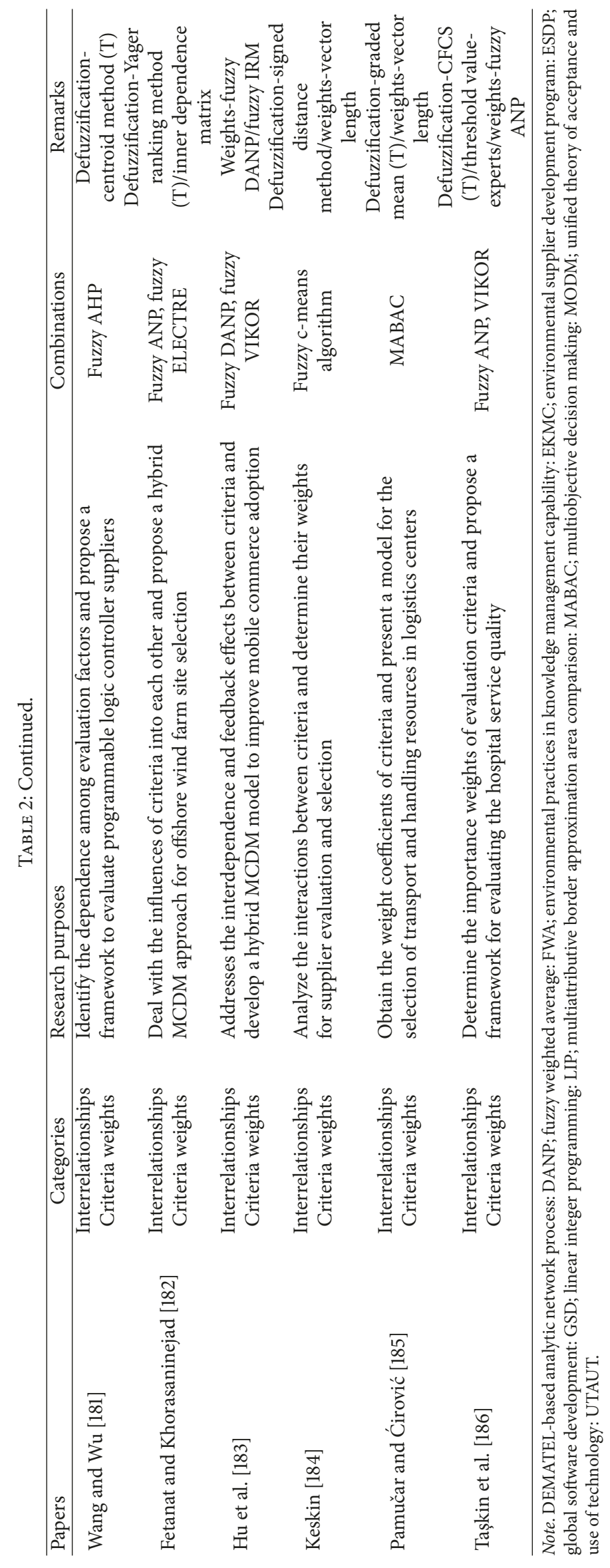


Step 3. Transform the group fuzzy assessments into crisp values and form the group direct-influence matrix $Z$.

Using a defuzzification method, the group directinfluence fuzzy matrix $\widetilde{Z}=\left[\widetilde{z}_{i j}\right]_{n \times n}$ can be defuzzified as a group direct-influence matrix $Z$. Or according to the CFCS (converting fuzzy data into crisp scores) method [215], the fuzzy assessments of experts $\widetilde{Z}_{k}(k=1,2, \ldots, l)$ on the pairwise relations between factors can be defuzzified and aggregated into crisp scores to construct the group directinfluence matrix $Z[126,130,132,134,136,137,139,142-$ $144,147-149,152]$.

Step 4. Apply the classical DEMATEL approach to

(i) establish the normalized direct-influence matrix $X$,

(ii) construct the total-influence matrix $T$,

(iii) produce the IRM.

From the group direct-influence matrix $Z$, the normalized direct-influence matrix $X$ can be arrived at by (2). Then, the total-influence matrix $T$ is obtained through (4). Finally, an IRM can be constructed by using (5), with the horizontal axis $(R+C)$ and the vertical axis $(R-C)$.

3.2.2. Fuzzy-Based DEMATEL. In this extended model, fuzzy logic is first employed to deal with the vagueness and imprecision involved in the influence degree estimation, then the DEMATEL analysis is completed, and finally the resulting fuzzy numbers are converted into numerical values for making decisions. The analytical procedure of fuzzybased DEMATEL model is described as follows [159, 171].

Step 1. Evaluate the relationships between factors using fuzzy linguistic scale.

Step 2. Establish the group direct-influence fuzzy matrix $\widetilde{Z}=$ $\left[\widetilde{z}_{i j}\right]_{n \times n}$.

Step 3. Generate the normalized direct-influence fuzzy matrix $\widetilde{X}$ by

$$
\widetilde{X}=\frac{\widetilde{Z}}{r}
$$

where

$$
\begin{aligned}
& \widetilde{X}=\left[\begin{array}{cccc}
\tilde{x}_{11} & \tilde{x}_{12} & \cdots & \tilde{x}_{1 n} \\
\tilde{x}_{21} & \tilde{x}_{22} & \cdots & \tilde{x}_{2 n} \\
\vdots & \vdots & \ddots & \vdots \\
\tilde{x}_{n 1} & \tilde{x}_{n 2} & \cdots & \tilde{x}_{n n}
\end{array}\right], \\
& r=\max _{1 \leq i \leq n}\left(\sum_{j=1}^{n} z_{i j 3}\right) .
\end{aligned}
$$

At least one $i$ is assumed such that $\sum_{j=1}^{n} z_{i j 3}<r$. Note that, in some studies $[157,159,160,162,166,176]$, the individual direct-influence fuzzy matrixes $\widetilde{Z}_{k}(k=1,2, \ldots, l)$ are normalized first and then aggregated via arithmetic mean to get the normalized direct-influence fuzzy matrix $\widetilde{X}$. In addition, formula (16) was utilized to normalize the group direct-influence fuzzy matrix $\widetilde{Z}$ in $[156,161,168,172,178,179$, 181, 183].

$$
r=\max _{i, j}\left[\max _{1 \leq i \leq n}\left(\sum_{j=1}^{n} z_{i j 3}\right), \max _{1 \leq j \leq n}\left(\sum_{i=1}^{n} z_{i j 3}\right)\right] .
$$

Step 4. Obtain the total-influence fuzzy matrix $\widetilde{T}=\left[\widetilde{t}_{i j}\right]_{n \times n}$ by

$$
\begin{aligned}
\widetilde{T}=\lim _{h \rightarrow \infty}\left(\widetilde{X}^{1}+\widetilde{X}^{2}+\cdots+\widetilde{X}^{h}\right)= & \widetilde{X}(1-\widetilde{X})^{-1}, \\
& \text { when } \lim _{h \rightarrow \infty} \widetilde{X}^{h}=O .
\end{aligned}
$$

Here $\tilde{t}_{i j}=\left(t_{i j 1}, t_{i j 2}, t_{i j 3}\right)$ and

$$
\begin{aligned}
& T_{1}=\left[t_{i j 1}\right]_{n \times n}=X_{1}\left(I-X_{1}\right)^{-1}, \\
& T_{2}=\left[t_{i j 2}\right]_{n \times n}=X_{2}\left(I-X_{2}\right)^{-1}, \\
& T_{3}=\left[t_{i j 3}\right]_{n \times n}=X_{3}\left(I-X_{3}\right)^{-1},
\end{aligned}
$$

in which $X_{1}=\left[x_{i j 1}\right]_{n \times n}, X_{2}=\left[x_{i j 2}\right]_{n \times n}, X_{3}=\left[x_{i j 3}\right]_{n \times n}$, and $I$ is an identity matrix. The elements of triangular fuzzy numbers in the matrix $\widetilde{T}$ are divided into $T_{1}, T_{2}$, and $T_{3}$, and $T_{1} \prec T_{2} \prec T_{3}$, when $x_{i j 1}<x_{i j 2}<x_{i j 3}$ for any $i, j \in$ $\{1,2, \ldots, n\}$.

Step 5. Produce the IRM.

Once the total-influence fuzzy matrix $\widetilde{T}$ is obtained, then $\widetilde{R}_{i}+\widetilde{C}_{i}$ and $\widetilde{R}_{i}-\widetilde{C}_{i}$ can be calculated easily in which $\widetilde{R}_{i}$ and $\widetilde{C}_{i}$ are the sum of rows and the sum of columns within the matrix $\widetilde{T}$, respectively. Next, the fuzzy numbers of $\widetilde{R}_{i}+\widetilde{C}_{i}$ and $\widetilde{R}_{i}-\widetilde{C}_{i}$ are converted into crisp numbers by using a defuzzification method. A causal diagram can be drawn like the classical DEMATEL by mapping the ordered pairs of $\left(\widetilde{R}_{i}+\widetilde{C}_{i}\right)^{\text {def }}$ and $\left(\widetilde{R}_{i}-\widetilde{C}_{i}\right)^{\text {def }}$.

In the above, the fuzzy numbers are not transformed until after calculating the prominence degree $\widetilde{R}_{i}+\widetilde{C}_{i}$ and the net effect $\widetilde{R}_{i}-\widetilde{C}_{i}$. But a defuzzification step was implemented in Step 4 by some researchers $[161,179,181,182]$ to defuzzify the total-influence fuzzy matrix $\widetilde{T}$ into the total-influence matrix $T$. The rest of the steps are the same as the original DEMETAL technique.

Generally, triangular fuzzy numbers were utilized in the fuzzy DEMETAL studies except [129, 177]. In [177], the authors developed an extension of fuzzy DEMATEL to trapezoidal membership functions to analyze the complex cause-effect relationships between variables in a composite indicator for disaster resilience. In [129], the authors employed a fuzzy DEMATEL methodology using trapezoidal fuzzy numbers for evaluating the enablers in solar power developments in India. 


\subsubsection{Observations and Findings}

(1) Defuzzification Methods. In the fuzzy DEMATEL literature, a variety of defuzzification methods have been employed for the factor interrelation analysis. Considering that the defuzzification of fuzzy numbers is very vital for the DEMATEL methodologies combined with fuzzy logic, we here conduct a survey on the defuzzification algorithms used in the fuzzy DEMATEL studies.

The CFCS method suggested by Opricovic and Tzeng [215] is the most prevalently adopted defuzzification algorithm in the fuzzy logic and DEMATEL models. For the fuzzy influence assessment $\widetilde{z}_{i j}^{k}=\left(z_{i j 1}^{k}, z_{i j 2}^{k}, z_{i j 3}^{k}\right)$ given by expert $E_{k}$, the defuzzification procedure based on the CFCS is performed as follows [130, 136, 138, 215, 216].

Step 1. Normalization of the fuzzy numbers:

$$
\begin{aligned}
& \bar{z}_{i j 1}^{k}=\frac{z_{i j 1}^{k}-\min z_{i j 1}^{k}}{\max z_{i j 3}^{k}-\min z_{i j 1}^{k}}, \\
& \bar{z}_{i j 2}^{k}=\frac{z_{i j 2}^{k}-\min z_{i j 1}^{k}}{\max z_{i j 3}^{k}-\min z_{i j 1}^{k}}, \\
& \bar{z}_{i j 3}^{k}=\frac{z_{i j 3}^{k}-\min z_{i j 1}^{k}}{\max z_{i j 3}^{k}-\min z_{i j 1}^{k}} .
\end{aligned}
$$

Step 2. Compute left and right normalized values:

$$
\begin{aligned}
& l z_{i j}^{k}=\frac{\bar{z}_{i j 2}^{k}}{1+\bar{z}_{i j 2}^{k}-\bar{z}_{i j 1}^{k}}, \\
& r z_{i j}^{k}=\frac{\bar{z}_{i j 3}^{k}}{1+\bar{z}_{i j 3}^{k}-\bar{z}_{i j 2}^{k}} .
\end{aligned}
$$

Step 3. Compute total normalized crisp value:

$$
t z_{i j}^{k}=\frac{l z_{i j}^{k}\left(1-l z_{i j}^{k}\right)+r z_{i j}^{k} r z_{i j}^{k}}{1-l z_{i j}^{k}+r z_{i j}^{k}}
$$

Step 4. Compute crisp values:

$$
z_{i j}^{k}=\min z_{i j 1}^{k}+t z_{i j}^{k}\left(\max z_{i j 3}^{k}-\min z_{i j 1}^{k}\right) .
$$

Then, the different judgments of $l$ experts are integrated to construct the group direct-influence matrix $Z$ by

$$
z_{i j}=\frac{1}{l} \sum_{k=1}^{l} z_{i j}^{k}
$$

In the fuzzy-based DEMATEL methods, the following CFCS method was applied to calculate the prominence $\left(\widetilde{R}_{i}+\right.$ $\left.\widetilde{C}_{i}\right)^{\text {def }}$ and the relation $\left(\widetilde{R}_{i}-\widetilde{C}_{i}\right)^{\text {def }}[159,162,164,167]$ :

$$
y_{i}=L+\Delta \times \frac{\left(m_{i}-L\right)\left(\Delta+u_{i}-m_{i}\right)^{2}\left(R-l_{i}\right)+\left(u_{i}-L\right)^{2}\left(\Delta+m_{i}-l_{i}\right)^{2}}{\left(\Delta+m_{i}-l_{i}\right)\left(\Delta+u_{i}-m_{i}\right)^{2}\left(R-l_{i}\right)+\left(u_{i}-L\right)\left(\Delta+m_{i}-l_{i}\right)^{2}\left(\Delta+u_{i}-m_{i}\right)},
$$

where $y_{i}$ denotes the defuzzified value of the fuzzy number $\tilde{y}_{i}=\left(l_{i}, m_{i}, u_{i}\right), L=\min l_{i}, R=\max u_{i}$ and $\Delta=R-L$.

The centroid method (center-of-gravity (COG) or center of area (COA)) was used to determine the crisp values of fuzzy numbers in $[131,158,165,170,179]$. For the triangular fuzzy number $\tilde{y}=(l, m, u)$, its crisp value can be found with the following equivalent relations:

$$
\begin{aligned}
y & =l+\frac{(m-l)+(u-l)}{3}, \\
\text { or } y & =\frac{l+m+u}{3} .
\end{aligned}
$$

In $[180,184]$, the signed distance of a fuzzy number (called signed distance method or Yager ranking method in [182]) shown in (29) was used as its defuzzified value. Patil and Kant [141] defuzzified each fuzzy number into a crisp value by using the graded mean integration representation method as (30). In [176], the defuzzification of fuzzy numbers is carried out using (31) to compute the point that divides the area of a fuzzy set into two equal parts.

$$
y=\frac{l+2 m+u}{4}
$$

$$
\begin{aligned}
& y=\frac{l+4 m+u}{6}, \\
& y= \begin{cases}u-\sqrt{\frac{(u-l)(u-m)}{2}}, & u-m>m-l, \\
\sqrt{\frac{(u-l)(u-m)}{2}}-l, & u-m<m-l, \\
m, & \text { otherwise. }\end{cases}
\end{aligned}
$$

(2) Weighting Methods. As shown in Table 2, many studies have applied the fuzzy DEMETAL to determine the weights of criteria considering their hierarchies, and a variety of weighting methods have been suggested. In addition to those methods already mentioned in the classical DEMETAL studies, that is, those based $R+C$ and dependency weights, some new weighting methods have been developed.

The vector length method has been used in [150, 176, 180, 184 ], which sets the importance of criteria with the following formula:

$$
\omega_{i}=\left[\left(\widetilde{R}_{i}^{\mathrm{def}}+\widetilde{C}_{i}^{\mathrm{def}}\right)^{2}+\left(\widetilde{R}_{i}^{\mathrm{def}}-\widetilde{C}_{i}^{\mathrm{def}}\right)^{2}\right]^{1 / 2} .
$$


Then the weight of any criterion can be normalized as follows:

$$
w_{i}=\frac{\omega_{i}}{\sum_{i=1}^{n} \omega_{i}}, \quad i=1,2, \ldots, n .
$$

Wang [179] evaluated the importance weights of criteria by normalizing their absolute relation values:

$$
w_{i}=\frac{\left|r_{i}-c_{i}\right|}{\sum_{i=1}^{n}\left|r_{i}-c_{i}\right|}, \quad i=1,2, \ldots, n .
$$

Here $\left|r_{i}-c_{i}\right|$ represents a signed relation value for the $j$ th criterion.

Besides, based on the interactions among criteria, fuzzy AHP was utilized by Wang and Wu [181] and Hsu et al. [171], fuzzy ANP was used by Taşkin et al. [186], Fetanat and Khorasaninejad [182], and Bakeshlou et al. [154], and fuzzy DEMATEL-based analytic network process (DANP) was employed by $\mathrm{Hu}$ et al. [183] to calculate relative weights of criteria.

3.3. Grey DEMATEL. Grey theory [35] is a mathematical theory proposed to cope with systems which lack information. It is an effective methodology to resolve uncertain and indeterminate problems and is superior in theoretical analysis of systems with discrete data and incomplete information. Hence, grey theory has been incorporated with the DEMATEL by some researchers for the evaluation of factor intertwined relations in real-life systems. To facilitate reading and comparison, the reviewed twelve grey DEMATEL studies are summarized in Table 3. All of them adopted grey DEMATEL methods for the identification of key factors through analyzing the interaffected relationships among them.

Similar to the fuzzy DEMATEL, there are mainly two types of grey DEMATEL methods, that is, the grey theory and DEMATEL and the grey-based DEMATEL. Fu et al. [187] first introduced the grey theory and DEMATEL methodology to investigate the importance of green supplier development programs at a telecommunications systems provider. The proposed method involves assessing interdependency relationships among factors by a grey linguistics scale, transforming grey numbers into single real numbers using a modified CFCS process, and eventually executing the classical DEMATEL steps to obtain an IRM with associated analysis. Later, the grey theory and DEMATEL method was applied by Dou and Sarkis [188] to evaluate the barriers of implementing China RoHS (the restriction of the use of hazardous substances in electrical and electronic equipment) regulations from a multiple stakeholder perspective, by Zhu et al. [189] to identify the supply chain-based barriers for truck-engine remanufacturing in China, by Rajesh and Ravi [190] to ascertain the major enablers of supply chain risk mitigation in electronic supply chains, by Shao et al. [191] to analyze the barriers between environmentally friendly products and consumers on the European automobile industry, by Govindan et al. [192] to develop important criteria for thirdparty logistics provider selection and evaluation, and by Xia et al. [193] to analyze the internal barriers for remanufacturers in the Chinese automotive sector.
Bai and Sarkis [194] argued that the data conversion process of the grey and DEMATEL method will cause a loss of original decision information, thus leading to unreasonable or misleading results in the final decision. Accordingly, they proposed a grey-based DEMATEL model to identify critical success factors (CFSs) in the successful implementation of business process management (BPM). In their integrated structural model, the authors evaluated various BPM implementation CSFs directly through the grey-based DEMATEL and did not "degrey" the grey numbers until after calculating the prominence and relation indexes. Liang et al. [195] also reported a grey-based DEMATEL for identifying the CFSs for promoting sustainable development of biofuel industry in China.

Additionally, Tseng [196] proposed a grey-fuzzy DEMATEL approach based on a grey possibility degree to deal with real estate agent service quality expectation ranking with uncertainty. Su et al. [197] developed a hierarchical grey DEMATEL methodology for improving sustainable supply chain management under hierarchical structure interrelationships and incomplete information. Ozcan and Tuysuz [197] elaborated upon a grey-based multicriteria performance evaluation model for retail stores by integrating DEMATEL and GRA methods.

It is worth noting that different from the threshold determination methods mentioned in the traditional DEMATEL part, the threshold value $\theta$ in the grey DEMATEL papers was usually yielded based on the mean $(\mu)$ and standard deviation $(\sigma)$ of the values from the total-influence matrix $T$. For example, in $[187,191,193,194]$, the threshold is set up by computing the sum of the mean and standard deviation $(\mu+\sigma)$. Rajesh and Ravi [190] set the threshold value by adding 1.5 times the standard deviation to the mean $(\mu+1.5 \sigma)$ and Zhu et al. [189] added two standard deviations to the mean $(\mu+2 \sigma)$ to calculate the value of $\theta$.

3.4. Other DEMATEL Methods. In previous sections, we have overviewed the DEMATEL for decision making under different contexts, that is, the original crisp DEMATEL, the fuzzy DEMATEL, and the grey DEMATEL. Recently, various approaches that combine other new uncertain theories with DEMATEL have been put forward to enhance its analysis capability and practicality. Table 4 shows those modifications identified in the literature and, in the sequence, a detailed literature analysis is given.

Jenab et al. [199] proposed an interval DEMATEL (i-DEMATEL) method for evaluating and implementing computer integrated manufacturing technologies that takes into account all decision parameters. Abdullah and Zulkifli [200] reported an interval type 2 fuzzy DEMATEL (IT2fuzzy DEMATEL) and combined it with fuzzy AHP for human resource management, where interval type 2 trapezoidal fuzzy numbers were used to resolve the relationships among dimensions and criteria. Nikjoo and Saeedpoor [201] presented an intuitionistic fuzzy DEMATEL approach to determine the key components of strengths, weaknesses, opportunities, and threats (SWOT) matrix, and Govindan et al. [202] used the DEMATEL method with intuitionistic fuzzy sets (IFSs) to handle the important and causal relationships 


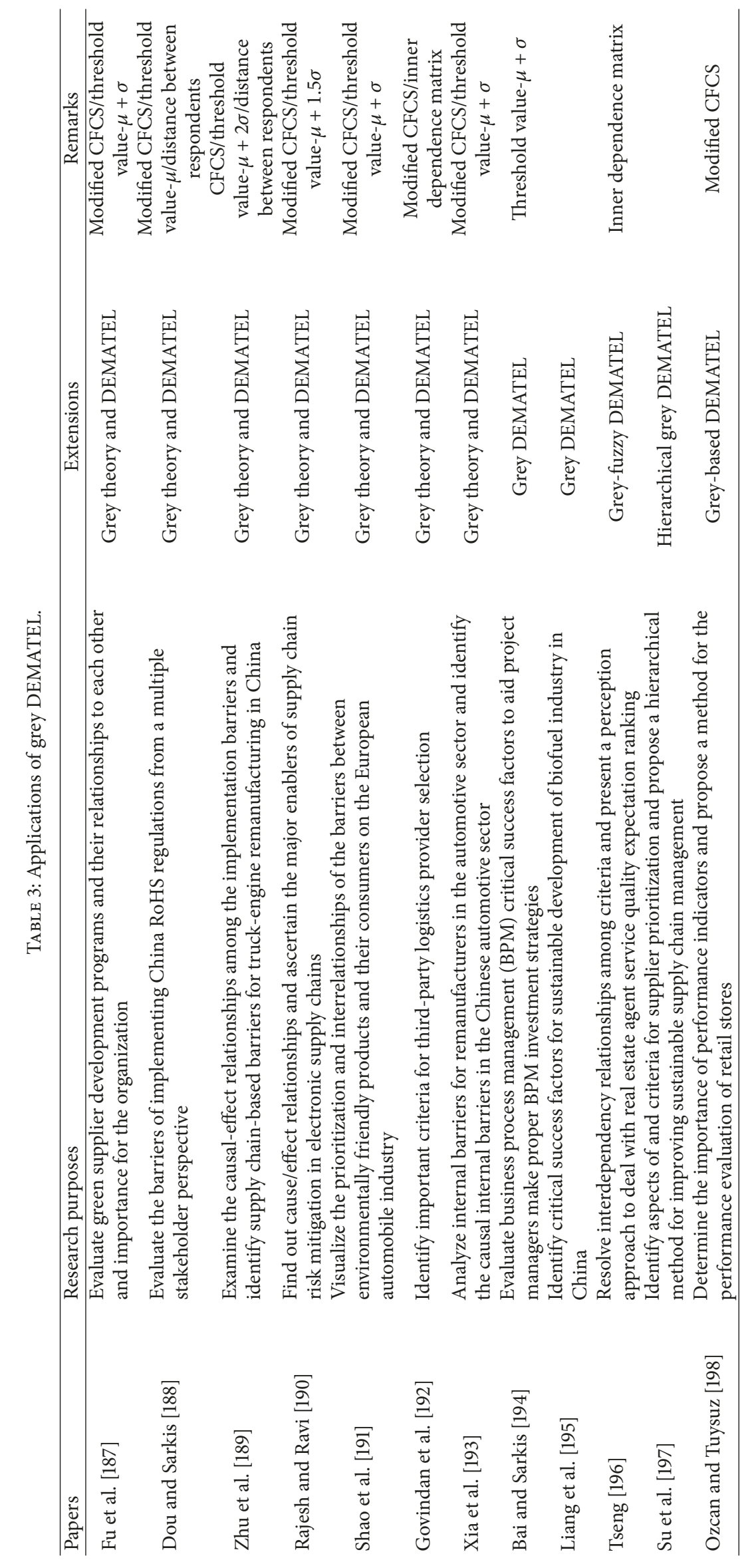




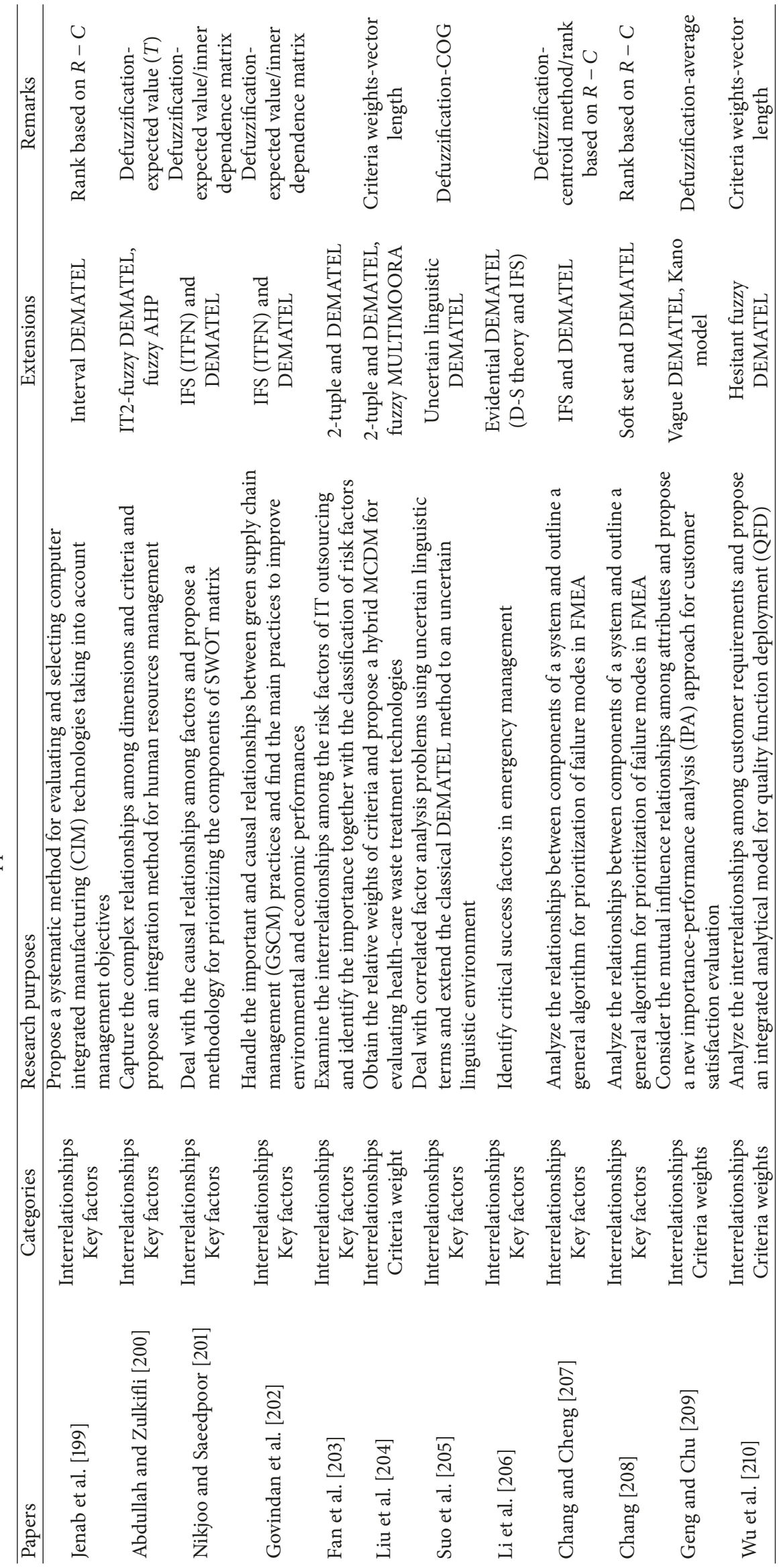


between green practices and performances in green supply chain management. Fan et al. [203] developed an extended DEMATEL method using 2-tuple fuzzy linguistic representation model to identify risk factors of IT outsourcing, and Liu et al. [204] utilized a 2-tuple DEMATEL technique to compute the importance weights of criteria and proposed a hybrid MCDM model for evaluating health-care waste treatment technologies.

Suo et al. [205] presented an extension of DEMATEL method in an uncertain linguistic environment, which allows the judgments on the correlations between factors in the form of uncertain linguistic terms. Li et al. [206] proposed an evidential DEMATEL method for identifying CFSs in emergency management, in which the evaluations of influencing factors expressed in intuitionistic fuzzy numbers (IFNs) were transformed into basic probability assignments (BPAs) and Dempster-Shafer (D-S) theory was used to obtain the group assessment BPA matrix. Chang and Cheng [207] suggested an efficient algorithm which combines IFSs and the DEMATEL to evaluate the risk of failure modes and Chang [208] proposed a risk ranking model integrating soft set theory and the DEMATEL technique for the risk assessment in failure mode and effect analysis (FMEA). Geng and Chu [209] dealt with the uncertainty and vagueness of expert evaluations by using vague sets and presented a revised DEMATEL approach to capture the mutual influence relationships among quality attributes. Then, a new importanceperformance analysis (IPA) method for customer satisfaction evaluation was proposed based on Kano model and vague DEMATEL. Wu et al. [210] presented an integrated analytical model for QFD, in which hesitant fuzzy DEMATEL was adopted to analyze the interrelationships among customer requirements and determine their weights.

\section{Bibliometric Analysis}

Based on the collected papers on the DEMATEL, a bibliometric analysis is conducted in this section regarding quantity of articles published per year, application areas of DEMATEL, and the highly cited papers. The intention of this bibliometric analysis is to find out current research trends, distribution of the articles in different categories, and interactions with other fields, which provide valuable insights for researchers and practitioners working in this field. First, from Figure 4, one can observe that the number of publications on DEMATEL has increased considerably, especially after the year 2009. It can be expected that the studies of utilizing the DEMATEL and its variants will continue to grow at an increased pace in the coming decade. Figure 4 also shows the trend in the number of publications in each category. It can be found that the classical and the fuzzy DEMATEL methods are mostly used for decision making in the earlier literature. It was only after the year 2010 when the focus shifted to employing the combination of ANP and DEMATEL. However, the usage of the classical and the fuzzy DEMATEL methods has continued to grow until more recently when some papers began to deal with the grey and other DEMATEL applications. Normally, if the relationships of systems are given by crisp values in

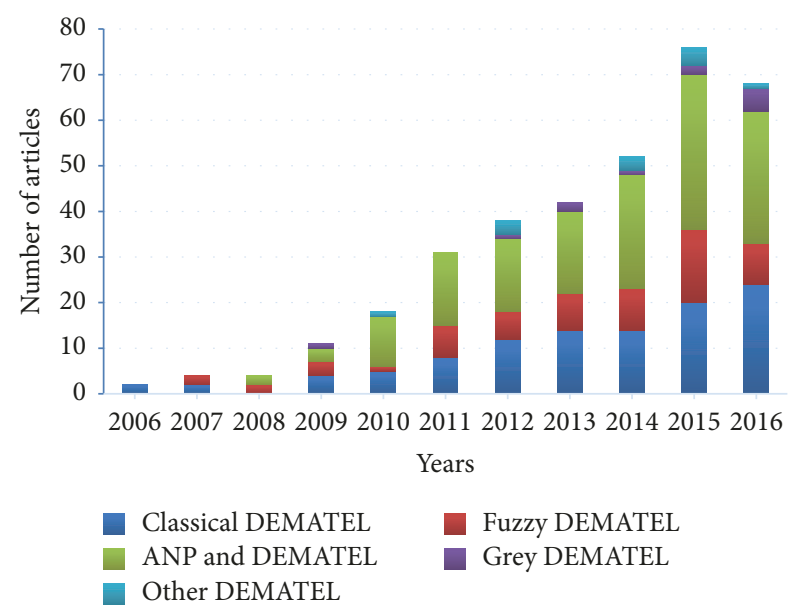

FIGURE 4: Distribution of articles according to the years.

TABLE 5: The top ten papers based on citation measures.

\begin{tabular}{lcc}
\hline Papers & Total citation & Average citation \\
\hline Tzeng et al. [10] & 334 & 41.75 \\
Wu and Lee [130] & 224 & 28.00 \\
Lin and Wu [159] & 166 & 23.71 \\
Wu [211] & 162 & 23.14 \\
Huang et al. [8] & 131 & 16.38 \\
Büyüközkan and Çifçi [212] & 128 & 42.67 \\
Tsai and Chou [213] & 128 & 21.33 \\
Seyed-Hosseini et al. [77] & 128 & 14.22 \\
Chiu et al. [49] & 128 & 14.22 \\
Chang et al. [134] & 83 & 20.75 \\
\hline
\end{tabular}

establishing a structural model, the classical DEMATEL can be used for evaluating problems and decision making [217]. For the cases that the human judgments about preferences are unclear and hard to estimate by exact numerical values, the fuzzy DEMATEL is necessary for making better decisions in fuzzy environments. The grey DEMATEL can be applied to the systems with limited data and incomplete information, which may exhibit random uncertainty.

From Figure 5, we can see that the DEMATEL and its various improvements have been widely used in a lot of areas, practically in computer science $(40.6 \%)$, engineering (35.7\%), business and managements (26.4\%), decision sciences (17.7\%), and social sciences (15.5\%).

In Table 5, the top ten papers are given by analyzing the total citation and average citation of each publication. "Total citation" refers to the number of Scopus citations for a paper until 2016, and "average citation" or called "citation per year" is equal to the total citation divided by the number of years from publication. It can be seen that the most influenced papers in this filed are Tzeng et al. [10], Wu and Lee [130], Lin and Wu [159], Wu [211], Huang et al. [8], and Büyüközkan and Çifçi [212]. Note that the ranking of articles based upon the total citation does not necessarily match the average citation ranking. Besides, it can be observed that all the highly cited studies are at least five years old except Büyüközkan 


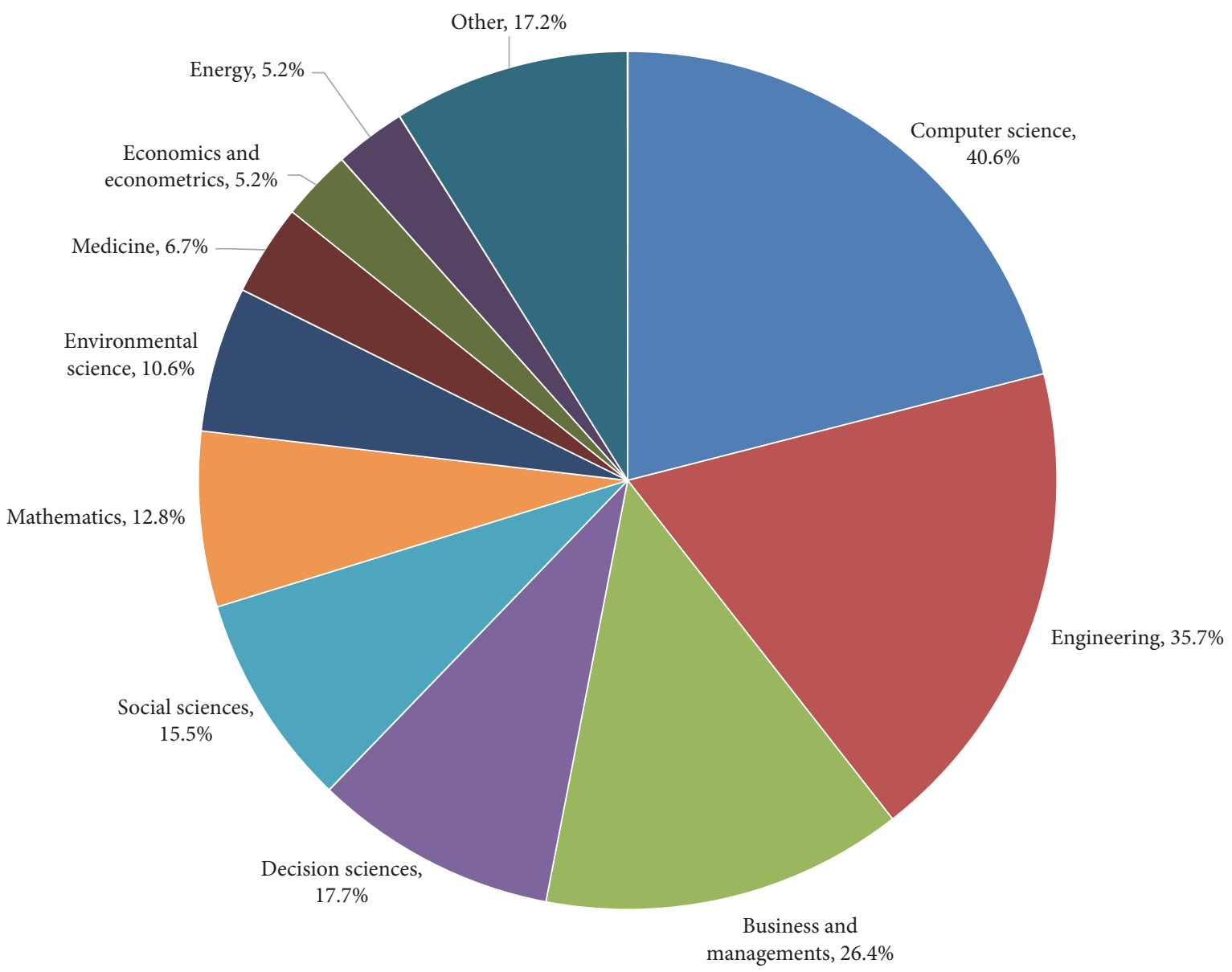

FIgURE 5: Distribution of articles according to application areas.

and Çifçi [212]. This is because sufficient time is usually needed for an influential paper to establish citations.

\section{Conclusions and Suggestions for Future Work}

In recent decade, the DEMATEL technique has attracted a lot of attention from both practitioners and researchers and has been used in a wide range of areas due to its ability to handle complex relationships between components of a system. In this paper, a representative and comprehensive review on the DEMATEL methods and applications from 2006 to 2016 was provided. According to the distinct forms of the DEMATEL used in the selected publications, five categories are identified and carefully investigated along with their main steps and characteristics. This review uncovers the current state of the research on this area based on statistical analysis results of the DEMATEL literature. It can be expected that the number of approaches and applications of the DEMATEL will continue to grow in the future due to its distinguished power and the increasing complexity of decision making problems.

Through the detailed review regarding the DEMATEL methodologies, the following possible future research directions for both theory and applications are suggested. First, to represent uncertainty and vagueness within the decision making process, the original DEMATEL was mainly combined with fuzzy sets and grey theory and only a few studies applied other uncertain theories, such as interval type 2 fuzzy sets, IFSs, 2-tuples and uncertain linguistic terms, to improve the DEMATEL recently. In the future, investigating the combination of DEMATEL with more advanced uncertain theories, such as hesitant fuzzy linguistic term sets and cloud model theory, for better decisions in uncertainty would be interesting. Second, the relative weights of decision makers are assumed to be equally important in computing the group direct-influence matrix $Z$. However, in practical situations, decision makers usually come from different specialty fields and each expert has unique characteristics with regard to knowledge, skills, experience, and personality, which implies that different expert weights should be assigned to reflect their influences on final analysis results. Moreover, in the interrelationship evaluation process, some decision makers may assign unduly high or unduly low preference values to their "preferred" or "repugnant" factors. Thus, in the future, advanced DEMATEL methods should be developed to relieve the influence of unfair arguments on the decision results. Third, proposing more objective and effective methods is required to set the crucial parameters in DEMATEL such as 
threshold value $\theta$ and criteria weights in further research. For example, although different methods have been suggested to determine the value of $\theta$ in current DEMATEL studies, these methods are subjective and time-consuming [218].

From the perspective of applications, our study also has several implications for further research. First, the literature review shows that a series of modified DEMATEL approaches have been developed, but no or few studies have been done to compare between the methods in the same or different groups. So, one recommendation for future research is the evaluation and comparison of the advantages and drawbacks of different DEMATEL methods in order to aid practitioners to select the suitable one for the problem to be solved. Second, to analyze the complicated interrelations between factors accurately, many computations are involved in the extended DEMATEL models, which limit their applications. Thus, a software tool should be developed in the future to facilitate the implementation of the DEMATEL technique. Finally, future research could apply the DEMATEL methodology and its variants to other situations and broader fields that are not considered in the previous studies.

\section{Conflicts of Interest}

The authors declare no conflicts of interest.

\section{Acknowledgments}

This work was supported by the National Natural Science Foundation of China (nos. 61773250 and 71402090), the Shanghai Pujiang Talents Program (no. 15PJC050), and the Program for Professor of Special Appointment (Young Eastern Scholar) at Shanghai Institutions of Higher Learning (no. QD2015019).

\section{References}

[1] A. Gabus and E. Fontela, World Problems, An Invitation to Further Thought within The Framework of DEMATEL, Battelle Geneva Research Centre, Geneva, Switzerland, 1972.

[2] A. Mardani, E. K. Zavadskas, Z. Khalifah et al., "A review of multi-criteria decision-making applications to solve energy management problems: two decades from 1995 to 2015," Renewable \& Sustainable Energy Reviews, vol. 71, pp. 216-256, 2017.

[3] M. Zare, C. Pahl, H. Rahnama et al., "Multi-criteria decision making approach in E-learning: a systematic review and classification," Applied Soft Computing, vol. 45, pp. 108-128, 2016.

[4] E. Falatoonitoosi, S. Ahmed, and S. Sorooshian, "Expanded DEMATEL for determining cause and effect group in bidirectional relations," The Scientific World Journal, vol. 2014, Article ID 103846, pp. 1-7, 2014.

[5] H.-S. Lee, G.-H. Tzeng, W. Yeih, Y.-J. Wang, and S.-C. Yang, "Revised DEMATEL: resolving the infeasibility of DEMATEL," Applied Mathematical Modelling, vol. 37, no. 10-11, pp. 67466757, 2013.

[6] G.-H. Tzeng, W.-H. Chen, R. Yu, and M.-L. Shih, "Fuzzy decision maps: a generalization of the DEMATEL methods," Soft Computing, vol. 14, no. 11, pp. 1141-1150, 2010.
[7] İ. Gölcük and A. Baykasoğlu, "An analysis of DEMATEL approaches for criteria interaction handling within ANP," Expert Systems with Applications, vol. 46, pp. 346-366, 2016.

[8] C.-Y. Huang, J. Z. Shyu, and G.-H. Tzeng, "Reconfiguring the innovation policy portfolios for Taiwan/s SIP mall industry," Technovation, vol. 27, no. 12, pp. 744-765, 2007.

[9] C.-W. Li and G.-H. Tzeng, "Identification of interrelationship of key customers' needs based on structural model for services/capabilities provided by a Semiconductor-IntellectualProperty Mall," Applied Mathematics and Computation, vol. 215, no. 6, pp. 2001-2010, 2009.

[10] G. H. Tzeng, C. H. Chiang, and C. W. Li, "Evaluating intertwined effects in e-learning programs: a novel hybrid MCDM model based on factor analysis and DEMATEL," Expert Systems with Applications, vol. 32, no. 4, pp. 1028-1044, 2007.

[11] C. Lin and G. Tzeng, "A value-created system of science (technology) park by using DEMATEL," Expert Systems with Applications, vol. 36, no. 6, pp. 9683-9697, 2009.

[12] A. Azadeh, M. Zarrin, M. Abdollahi, S. Noury, and S. Farahmand, "Leanness assessment and optimization by fuzzy cognitive map and multivariate analysis," Expert Systems with Applications, vol. 42, no. 15-16, pp. 6050-6064, 2015.

[13] P. T.-W. Lee and C.-W. Lin, "The cognition map of financial ratios of shipping companies using DEMATEL and MMDE," Maritime Policy \& Management, vol. 40, no. 2, pp. 133-145, 2013.

[14] J. Sara, R. M. Stikkelman, and P. M. Herder, "Assessing relative importance and mutual influence of barriers for CCS deployment of the ROAD project using AHP and DEMATEL methods," International Journal of Greenhouse Gas Control, vol. 41, pp. 336-357, 2015.

[15] W.-K. Tan and C.-Y. Kuo, "Prioritization of facilitation strategies of park and recreation agencies through DEMATEL analysis," Asia Pacific Journal of Tourism Research, vol. 19, no. 8, pp. 859875, 2014.

[16] M. N. Shaik and W. Abdul-Kader, "Comprehensive performance measurement and causal-effect decision making model for reverse logistics enterprise," Computers \& Industrial Engineering, vol. 68, no. 1, pp. 87-103, 2014.

[17] S. M. Seyedhosseini, A. E. Taleghani, A. Bakhsha, and S. Partovi, "Extracting leanness criteria by employing the concept of balanced scorecard," Expert Systems with Applications, vol. 38, no. 8, pp. 10454-10461, 2011.

[18] G. T. R. Lin and C.-C. Sun, "Driving industrial clusters to be nationally competitive," Technology Analysis and Strategic Management, vol. 22, no. 1, pp. 81-97, 2010.

[19] S. Tzeng, "Applying DEMATEL to investigate the relationship between factors affecting parole boards' decision-making in Taiwan," The Prison Journal, vol. 94, no. 1, pp. 118-136, 2014.

[20] W. Hwang, B. Hsiao, H.-G. Chen, and C.-C. Chern, "Multiphase assessment of project risk interdependencies: evidence from a University ISD project in Taiwan," Project Management Journal, vol. 47, no. 1, pp. 59-75, 2016.

[21] H.-M. Chuang, C.-K. Lin, D.-R. Chen, and Y.-S. Chen, "Evolving MCDM applications using hybrid expert-based ISM and DEMATEL models: an example of sustainable ecotourism," The Scientific World Journal, vol. 2013, Article ID 751728, pp. 1-18, 2013.

[22] K.-F. Chien, Z.-H. Wu, and S.-C. Huang, "Identifying and assessing critical risk factors for BIM projects: empirical study," Automation in Construction, vol. 45, pp. 1-15, 2014. 
[23] W.-W. Wu, L. W. Lan, and Y.-T. Lee, "Exploring decisive factors affecting an organization's SaaS adoption: a case study," International Journal of Information Management, vol. 31, no. 6, pp. 556-563, 2011.

[24] W.-W. Wu, L. W. Lan, and Y.-T. Lee, "Factors hindering acceptance of using cloud services in university: a case study," Electronic Library, vol. 31, no. 1, pp. 84-98, 2013.

[25] W.-C. Wang, Y.-H. Lin, C.-L. Lin, C.-H. Chung, and M.-T. Lee, "DEMATEL-based model to improve the performance in a matrix organization," Expert Systems with Applications, vol. 39, no. 5, pp. 4978-4986, 2012.

[26] W.-C. Wang, C.-L. Lin, S.-H. Wang, J.-J. Liu, and M.-T. Lee, "Application of importance-satisfaction analysis and influencerelations map to evaluate design delay factors," Journal of Civil Engineering and Management, vol. 20, no. 4, pp. 497-510, 2014.

[27] S. Cebi, "Determining importance degrees of website design parameters based on interactions and types of websites," Decision Support Systems, vol. 54, no. 2, pp. 1030-1043, 2013.

[28] A. Yazdani-Chamzini, S. Shariati, S. H. Yakhchali, and E. K. Zavadskas, "Proposing a new methodology for prioritising the investment strategies in the private sector of Iran," Economic Research-Ekonomska Istrazivanja, vol. 27, no. 1, pp. 320-345, 2014.

[29] B. Khazai, M. Merz, C. Schulz, and D. Borst, "An integrated indicator framework for spatial assessment of industrial and social vulnerability to indirect disaster losses," Natural Hazards, vol. 67, no. 2, pp. 145-167, 2013.

[30] A. Mardani, A. Jusoh, and E. K. Zavadskas, "Fuzzy multiple criteria decision-making techniques and applications-two decades review from 1994 to 2014," Expert Systems with Applications, vol. 42, no. 8, pp. 4126-4148, 2015.

[31] A. Mardani, A. Jusoh, K. MD Nor, Z. Khalifah, N. Zakwan, and A. Valipour, "Multiple criteria decision-making techniques and their applications-a review of the literature from 2000 to 2014," Economic Research-Ekonomska Istraživanja, vol. 28, no. 1, pp. 516-571, 2015.

[32] E. K. Zavadskas, Z. Turskis, and S. Kildiene, "State of art surveys of overviews on MCDM/MADM methods," Technological and Economic Development of Economy, vol. 20, no. 1, pp. 165-179, 2014.

[33] G. Kou, D. Ergu, C. Lin, and Y. Chen, "Pairwise comparison matrix in multiple criteria decision making," Technological and Economic Development of Economy, vol. 22, no. 5, pp. 738-765, 2016.

[34] G. Kou and C. Lin, "A cosine maximization method for the priority vector derivation in AHP," European Journal of Operational Research, vol. 235, no. 1, pp. 225-232, 2014.

[35] J. L. Deng, "Introduction to grey system theory," The Journal of Grey System, vol. 1, no. 1, pp. 1-24, 1989.

[36] S. Opricovic and G. H. Tzeng, "Compromise solution by MCDM methods: a comparative analysis of VIKOR and TOPSIS," European Journal of Operational Research, vol. 156, no. 2, pp. 445-455, 2004.

[37] E. K. Zavadskas, A. Mardani, Z. Turskis, A. Jusoh, and K. M. Nor, "Development of TOPSIS method to solve complicated decision-making problems - an overview on developments from 2000 to 2015," International Journal of Information Technology \& Decision Making, vol. 15, no. 3, pp. 645-682, 2016.

[38] B. Roy and P. Vincke, "Multicriteria analysis: survey and new directions," European Journal of Operational Research, vol. 8, no. 3, pp. 207-218, 1981.
[39] H.-C. Liu, J.-X. You, L. Zhen, and X.-J. Fan, "A novel hybrid multiple criteria decision making model for material selection with target-based criteria," Materials and Corrosion, vol. 60, pp. 380-390, 2014.

[40] Y. P. Ou Yang, H. M. Shieh, J. D. Leu, and G. H. Tzeng, "A novel hybrid MCDM model combined with DEMATEL and ANP with applications," International Journal of Operations Research, vol. 5, no. 3, pp. 160-168, 2008.

[41] G. Kou, D. Ergu, and J. Shang, "Enhancing data consistency in decision matrix: adapting Hadamard model to mitigate judgment contradiction," European Journal of Operational Research, vol. 236, no. 1, pp. 261-271, 2014.

[42] B. Efe and Ö. F. Efe, "An application of value analysis for lean healthcare management in an emergency department," International Journal of Computational Intelligence Systems, vol. 9, no. 4, pp. 689-697, 2016.

[43] G. Malekzadeh, M. Kazemi, M. Lagzian, and S. Mortazavi, "Modeling organizational intelligence using DEMATEL method in Iranian public universities," Journal of Modelling in Management, vol. 11, no. 1, pp. 134-153, 2016.

[44] R. Ranjan, P. Chatterjee, and S. Chakraborty, "Performance evaluation of Indian Railway zones using DEMATEL and VIKOR methods," Benchmarking, vol. 23, no. 1, pp. 78-95, 2016.

[45] H.-Y. Hu, Y.-C. Lee, T.-M. Yen, and C.-H. Tsai, "Using BPNN and DEMATEL to modify importance-performance analysis model - a study of the computer industry," Expert Systems with Applications, vol. 36, no. 6, pp. 9969-9979, 2009.

[46] H.-Y. Hu, S.-I. Chiu, C.-C. Cheng, and T.-M. Yen, "Applying the IPA and DEMATEL models to improve the order-winner criteria: a case study of Taiwan's network communication equipment manufacturing industry," Expert Systems with Applications, vol. 38, no. 8, pp. 9674-9683, 2011.

[47] C.-C. Cheng, C.-T. Chen, F.-S. Hsu, and H.-Y. Hu, "Enhancing service quality improvement strategies of fine-dining restaurants: new insights from integrating a two-phase decisionmaking model of IPGA and DEMATEL analysis," International Journal of Hospitality Management, vol. 31, no. 4, pp. 1155-1166, 2012.

[48] P.-L. Hsieh and T.-M. Yeh, "Developing a cause and effect model of factors influencing fast food restaurants' service quality using DEMATEL," International Journal of Services and Operations Management, vol. 20, no. 1, pp. 21-42, 2015.

[49] Y. J. Chiu, H. C. Chen, G. H. Tzeng, and J. Z. Shyu, "Marketing strategy based on customer behaviour for the LCD-TV," International Journal of Management and Decision Making, vol. 7, no. 2-3, pp. 143-165, 2006.

[50] L.-H. Ho, S.-Y. Feng, Y.-C. Lee, and T.-M. Yen, "Using modified IPA to evaluate supplier's performance: multiple regression analysis and DEMATEL approach," Expert Systems with Applications, vol. 39, no. 8, pp. 7102-7109, 2012.

[51] S.-B. Tsai, C.-Y. Huang, C.-K. Wang et al., "Using a mixed model to evaluate job satisfaction in high-tech industries," PLoS ONE, vol. 11, no. 5, Article ID e0154071, 2016.

[52] A. Najmi and A. Makui, "A conceptual model for measuring supply chain's performance," Production Planning and Control, vol. 23, no. 9, pp. 694-706, 2012.

[53] M. Shafiee, F. Hosseinzadeh Lotfi, and H. Saleh, "Supply chain performance evaluation with data envelopment analysis and balanced scorecard approach," Applied Mathematical Modelling, vol. 38, no. 21-22, pp. 5092-5112, 2014. 
[54] C.-H. Wang and O.-Z. Hsueh, "A novel approach to incorporate customer preference and perception into product configuration: a case study on smart pads," Computer Standards \& Interfaces, vol. 35, no. 5, pp. 549-556, 2013.

[55] C.-H. Wang and C.-W. Shih, "Integrating conjoint analysis with quality function deployment to carry out customer-driven concept development for ultrabooks," Computer Standards \& Interfaces, vol. 36, no. 1, pp. 89-96, 2013.

[56] S.-S. Ko, N. Ko, D. Kim, H. Park, and J. Yoon, "Analyzing technology impact networks for R\&D planning using patents: combined application of network approaches," Scientometrics, vol. 101, no. 1, pp. 917-936, 2014.

[57] J. Yoon, M. Kim, D. Kim, J. Kim, and H. Park, "Monitoring the change of technological impacts of technology sectors using patent information: the case of Korea," Industrial Engineering \& Management Systems, vol. 14, no. 1, pp. 58-72, 2015.

[58] K.-Y. Shen and G.-H. Tzeng, "Combined soft computing model for value stock selection based on fundamental analysis," Applied Soft Computing, vol. 37, pp. 142-155, 2015.

[59] S. Altuntas and T. Dereli, "A novel approach based on DEMATEL method and patent citation analysis for prioritizing a portfolio of investment projects," Expert Systems with Applications, vol. 42, no. 3, pp. 1003-1012, 2015.

[60] K.-Y. Shen and G.-H. Tzeng, "A new approach and insightful financial diagnoses for the IT industry based on a hybrid MADM model," Knowledge-Based Systems, vol. 85, pp. 112-130, 2015.

[61] W.-K. Tan and Y.-J. Tan, "Transformation of smart-card-based single-purpose e-micropayment scheme to multi-purpose scheme: a case study," Expert Systems with Applications, vol. 39, no. 3, pp. 2306-2313, 2012.

[62] C.-S. Liaw, Y.-C. Chang, K.-H. Chang, and T.-Y. Chang, "MEOWA based DEMATEL reliability apportionment method," Expert Systems with Applications, vol. 38, no. 8, pp. 9713-9723, 2011.

[63] A. A. R. Alaei and Y. V. Alroaia, "Identifying and prioritizing the factors affecting and affected by the performance of small and medium enterprises by using DEMATEL technique (The case study of a province in Iran)," Indian Journal of Science and Technology, vol. 9, no. 6, 2016.

[64] L. R. Bacudio, M. F. D. Benjamin, R. C. P. Eusebio et al., "Analyzing barriers to implementing industrial symbiosis networks using DEMATEL," Sustainable Production and Consumption, vol. 7, pp. 57-65, 2016.

[65] D. Balkovskaya and L. Filneva, "The use of the balanced scorecard in bank strategic management," International Journal of Business Excellence, vol. 9, no. 1, pp. 48-67, 2016.

[66] Y.-T. Chen, "Applying the DEMATEL approach to identify the focus of library service quality: a case study of a Taiwanese academic library," Electronic Library, vol. 34, no. 2, pp. 315-331, 2016.

[67] K. Govindan and A. Chaudhuri, "Interrelationships of risks faced by third party logistics service providers: a DEMATEL based approach," Transportation Research Part E: Logistics and Transportation Review, vol. 90, pp. 177-195, 2016.

[68] K. Govindan, K. Muduli, K. Devika, and A. Barve, "Investigation of the influential strength of factors on adoption of green supply chain management practices: an Indian mining scenario," Resources, Conservation \& Recycling, vol. 107, pp. 185194, 2016.

[69] S. Gandhi, S. K. Mangla, P. Kumar, and D. Kumar, "A combined approach using AHP and DEMATEL for evaluating success factors in implementation of green supply chain management in Indian manufacturing industries," International Journal of Logistics Research and Applications, vol. 19, no. 6, pp. 537-561, 2016.

[70] B.-N. Hwang, C.-Y. Huang, and C.-H. Wu, "A TOE approach to establish a green supply chain adoption decision model in the semiconductor industry," Sustainability, vol. 8, no. 2, article 168, 2016.

[71] B.-N. Hwang, C.-Y. Huang, and C.-L. Yang, "Determinants and their causal relationships affecting the adoption of cloud computing in science and technology institutions," Innovation, vol. 18, no. 2, pp. 164-190, 2016.

[72] F. Rahimnia and N. Kargozar, "Objectives priority in university strategy map for resource allocation," Benchmarking, vol. 23, no. 2, pp. 371-387, 2016.

[73] C. Sekhar, M. Patwardhan, and V. Vyas, "A study of HR flexibility and firm performance: a perspective from IT industry," Global Journal of Flexible Systems Management, vol. 17, no. 1, pp. 57-75, 2016.

[74] S. N. Seleem, E.-A. Attia, and A. El-Assal, "Managing performance improvement initiatives using DEMATEL method with application case study," Production Planning and Control, vol. 27, no. 7-8, pp. 637-649, 2016.

[75] V. Sharma, A. R. Dixit, and M. A. Qadri, "Empirical assessment of the causal relationships among lean criteria using DEMATEL method," Benchmarking, vol. 23, no. 7, pp. 1834-1859, 2016.

[76] Y.-C. Shen, "Identifying the key barriers and their interrelationships impeding the university technology transfer in Taiwan: a multi-stakeholder perspective," Quality \& Quantity, vol. 51, no. 6, pp. 2865-2884, 2017.

[77] S. M. Seyed-Hosseini, N. Safaei, and M. J. Asgharpour, "Reprioritization of failures in a system failure mode and effects analysis by decision making trial and evaluation laboratory technique," Reliability Engineering \& System Safety, vol. 91, no. 8, pp. 872881, 2006.

[78] K.-H. Chang, "Evaluate the orderings of risk for failure problems using a more general RPN methodology," Microelectronics Reliability, vol. 49, no. 12, pp. 1586-1596, 2009.

[79] K. Chang, Y. Chang, and I. Tsai, "Enhancing FMEA assessment by integrating grey relational analysis and the decision making trial and evaluation laboratory approach," Engineering Failure Analysis, vol. 31, pp. 211-224, 2013.

[80] K.-H. Chang, Y.-C. Chang, and Y.-T. Lee, "Integrating TOPSIS and DEMATEL methods to rank the risk of failure of FMEA," International Journal of Information Technology \& Decision Making, vol. 13, no. 6, pp. 1229-1257, 2014.

[81] H.-C. Liu, J.-X. You, X.-F. Ding, and Q. Su, "Improving risk evaluation in FMEA with a hybrid multiple criteria decision making method," International Journal of Quality \& Reliability Management, vol. 32, no. 7, pp. 763-782, 2015.

[82] A. Mentes, H. Akyildiz, M. Yetkin, and N. Turkoglu, "A FSA based fuzzy DEMATEL approach for risk assessment of cargo ships at coasts and open seas of Turkey," Safety Science, vol. 79, pp. 1-10, 2015.

[83] J.-S. Horng, C.-H. Liu, S.-F. Chou, and C.-Y. Tsai, "Creativity as a critical criterion for future restaurant space design: developing a novel model with DEMATEL application," International Journal of Hospitality Management, vol. 33, no. 1, pp. 96-105, 2013.

[84] C.-T. Chen, W.-H. Lee, Y.-Y. Chang, and C.-C. Cheng, "The strategy for enhancing consumer intention to dine at green restaurants: three-phase decision-making model," Total Quality 
Management \& Business Excellence, vol. 28, no. 5-6, pp. 614-632, 2017.

[85] C.-C. Cheng, M.-C. Tsai, and C.-L. Lin, "Quality education service: put your feet in their shoes," Current Issues in Tourism, vol. 19, no. 11, pp. 1120-1135, 2016.

[86] J. I. Shieh, H. H. Wu, and K. K. Huang, "A DEMATEL method in identifying key success factors of hospital service quality," Knowledge-Based Systems, vol. 23, no. 3, pp. 277-282, 2010.

[87] R. Ranjan, P. Chatterjee, and S. Chakraborty, "Evaluating performance of engineering departments in an Indian University using DEMATEL and compromise ranking methods," OPSEARCH, vol. 52, no. 2, pp. 307-328, 2015.

[88] H.-H. Wu, H.-K. Chen, and J.-I. Shieh, "Evaluating performance criteria of employment service outreach program personnel by DEMATEL method," Expert Systems with Applications, vol. 37, no. 7, pp. 5219-5223, 2010.

[89] C. C. Sun, "An exploration of core competences of newly qualified nurses: a case study," Quality \& Quantity, vol. 48, no. 2, pp. 767-780, 2014.

[90] H.-H. Wu and Y.-N. Tsai, "A DEMATEL method to evaluate the causal relations among the criteria in auto spare parts industry," Applied Mathematics and Computation, vol. 218, no. 5, pp. 23342342, 2011.

[91] C.-C. Sun, "Identifying critical success factors in EDA industry using DEMATEL method," International Journal of Computational Intelligence Systems, vol. 8, no. 2, pp. 208-218, 2015.

[92] H. H. Wu and Y. N. Tsai, "An integrated approach of AHP and DEMATEL methods in evaluating the criteria of auto spare parts industry," International Journal of Systems Science, vol. 43, no. 11, pp. 2114-2124, 2012.

[93] P.-L. Wei, J.-H. Huang, G.-H. Tzeng, and S.-I. Wu, "Causal modeling of web-advertising effects by improving SEM based on dematel technique," International Journal of Information Technology \& Decision Making, vol. 9, no. 5, pp. 799-829, 2010.

[94] C.-C. Hsu, "Evaluation criteria for blog design and analysis of causal relationships using factor analysis and DEMATEL," Expert Systems with Applications, vol. 39, no. 1, pp. 187-193, 2012.

[95] C.-C. Hsu and Y.-S. Lee, "Exploring the critical factors influencing the quality of blog interfaces using the DecisionMaking Trial and Evaluation Laboratory (DEMATEL) method," Behaviour \& Information Technology, vol. 33, no. 2, pp. 183-193, 2014.

[96] Y.-C. Lee, Y.-F. Hsieh, and Y.-B. Guo, "Construct DTPB model by using DEMATEL: a study of a university library website," Program, vol. 47, no. 2, pp. 155-169, 2013.

[97] V. Pathari and R. Sonar, "Identifying linkages between statements in information security policy, procedures and controls," Information Management \& Computer Security, vol. 20, no. 4, pp. 264-280, 2012.

[98] A. Jafarnejad, M. Ansari, H. R. Youshanlouei, and M. M. Mood, "A hybrid MCDM approach for solving the ERP system selection problem with application to steel industry," International Journal of Enterprise Information Systems, vol. 8, no. 3, pp. 5473, 2012.

[99] Y. C. Tsai and Y. T. Cheng, "Analyzing key performance indicators (KPIs) for e-commerce and Internet marketing of elderly products: a review," Archives of Gerontology and Geriatrics, vol. 55, no. 1, pp. 126-132, 2012.

[100] Y.-T. Lin, Y.-H. Yang, J.-S. Kang, and H.-C. Yu, "Using DEMATEL method to explore the core competences and causal effect of the IC design service company: an empirical case study,"
Expert Systems with Applications, vol. 38, no. 5, pp. 6262-6268, 2011.

[101] S. Rahman and N. Subramanian, "Factors for implementing end-of-life computer recycling operations in reverse supply chains," International Journal of Production Economics, vol. 140, no. 1, pp. 239-248, 2012.

[102] C.-W. Hsu, T.-C. Kuo, S.-H. Chen, and A. H. Hu, "Using DEMATEL to develop a carbon management model of supplier selection in green supply chain management," Journal of Cleaner Production, vol. 56, pp. 164-172, 2013.

[103] E. Falatoonitoosi, S. Ahmed, and S. Sorooshian, "A multicriteria framework to evaluate supplier's greenness," Abstract and Applied Analysis, vol. 2014, Article ID 396923, pp. 1-12, 2014.

[104] J. Ren, A. Manzardo, S. Toniolo, and A. Scipioni, "Sustainability of hydrogen supply chain. Part I: identification of critical criteria and cause-effect analysis for enhancing the sustainability using DEMATEL," International Journal of Hydrogen Energy, vol. 38, no. 33, pp. 14159-14171, 2013.

[105] K. Muduli and A. Barve, "Establishment of a sustainable development framework in small scale mining supply chains in India," International Journal of Intelligent Enterprise, vol. 2, no. 1, pp. 84-100, 2013.

[106] H.-H. Wu and S.-Y. Chang, "A case study of using DEMATEL method to identify critical factors in green supply chain management," Applied Mathematics and Computation, vol. 256, pp. 394-403, 2015.

[107] P. K. Behera and K. Mukherjee, "Application of DEMATEL and MMDE for analyzing key: Influencing factors relevant to selection of supply chain coordination schemes," International Journal of Information Systems and Supply Chain Management, vol. 8, no. 2, pp. 49-69, 2015.

[108] S. Ahmed, S. Ahmed, M. R. H. Shumon, M. A. Quader, H. M. Cho, and M. I. Mahmud, "Prioritizing strategies for sustainable end-of-life vehicle management using combinatorial multicriteria decision making method," International Journal of Fuzzy Systems, vol. 18, no. 3, pp. 448-462, 2016.

[109] S. Ahmed, S. Ahmed, M. R. H. Shumon, E. Falatoonitoosi, and M. A. Quader, "A comparative decision-making model for sustainable end-of-life vehicle management alternative selection using AHP and extent analysis method on fuzzy AHP," International Journal of Sustainable Development \& World Ecology, vol. 23, no. 1, pp. 83-97, 2016.

[110] R. Miao, F. Xu, K. Zhang, and Z. Jiang, "Development of a multiscale model for customer perceived value of electric vehicles," International Journal of Production Research, vol. 52, no. 16, pp. 4820-4834, 2014.

[111] G. Lin, "The promotion and development of solar photovoltaic industry: discussion of its key factors," Distributed Generation and Alternative Energy Journal, vol. 26, no. 4, pp. 57-80, 2011.

[112] A. Azarnivand and N. Chitsaz, "Adaptive policy responses to water shortage mitigation in the arid regions-a systematic approach based on eDPSIR, DEMATEL, and MCDA," Environmental Modeling \& Assessment, vol. 187, article 23, 2015.

[113] Y. Chen, J. Liu, Y. Li, R. Sadiq, and Y. Deng, "RM-DEMATEL: a new methodology to identify the key factors in P M 2.5," Environmental Science and Pollution Research, vol. 22, no. 8, pp. 6372-6380, 2015.

[114] L. S. dos Muchangos, A. Tokai, and A. Hanashima, "Analyzing the structure of barriers to municipal solid waste management policy planning in Maputo city, Mozambique," Environmental Development, vol. 16, pp. 76-89, 2015. 
[115] W.-F. Guo, J. Zhou, C.-L. Yu et al., "Evaluating the green corporate social responsibility of manufacturing corporations from a green industry law perspective," International Journal of Production Research, vol. 53, no. 2, pp. 665-674, 2015.

[116] F. H. Chen and D.-J. Chi, "Application of a new DEMATEL to explore key factors of China's corporate social responsibility: evidence from accounting experts," Quality \& Quantity, vol. 49, no. 1, pp. 135-154, 2013.

[117] D.-S. Chang, S.-H. Chen, C.-W. Hsu, and A. H. Hu, "Identifying strategic factors of the implantation CSR in the airline industry: the case of Asia-Pacific airlines," Sustainability, vol. 7, no. 6, pp. 7762-7783, 2015.

[118] Y.-C. Lee, M.-L. Li, T.-M. Yen, and T.-H. Huang, "Analysis of adopting an integrated decision making trial and evaluation laboratory on a technology acceptance model," Expert Systems with Applications, vol. 37, no. 2, pp. 1745-1754, 2010.

[119] H. Y. Wu, "Constructing a strategy map for banking institutions with key performance indicators of the balanced scorecard," Evaluation and Program Planning, vol. 35, no. 3, pp. 303-320, 2012.

[120] Y. Gazibey, O. Kantemir, and A. Demirel, "Interaction among the criteria affecting main battle tank selection: An analysis with DEMATEL method," Defence Science Journal, vol. 65, no. 5, pp. 345-355, 2015.

[121] K. Khalili-Damghani, B. Aminzadeh-Goharrizi, S. Rastegar, and B. Aminzadeh-Goharrizi, "Solving land-use suitability analysis and planning problem by a hybrid meta-heuristic algorithm," International Journal of Geographical Information Science, vol. 28, no. 12, pp. 2390-2416, 2014.

[122] M.-L. Tseng, "Using hybrid MCDM to evaluate the service quality expectation in linguistic preference," Applied Soft Computing, vol. 11, no. 8, pp. 4551-4562, 2011.

[123] M. A. Quader, S. Ahmed, R. A. Raja Ghazilla, S. Ahmed, and M. Dahari, "Evaluation of criteria for $\mathrm{CO} 2$ capture and storage in the iron and steel industry using the 2-tuple DEMATEL technique," Journal of Cleaner Production, vol. 120, pp. 207-220, 2016.

[124] M. A. Quader and S. Ahmed, "A hybrid fuzzy MCDM approach to identify critical factors and $\mathrm{CO} 2$ capture technology for sustainable iron and steel manufacturing," Arabian Journal for Science and Engineering, vol. 41, no. 11, pp. 4411-4430, 2016.

[125] M. Kuo, "Optimal location selection for an international distribution center by using a new hybrid method," Expert Systems with Applications, vol. 38, no. 6, pp. 7208-7221, 2011.

[126] S. Altuntas, H. Selim, and T. Dereli, "A fuzzy DEMATEL-based solution approach for facility layout problem: a case study," The International Journal of Advanced Manufacturing Technology, vol. 73, no. 5-8, pp. 749-771, 2014.

[127] S. Altuntas and M. K. Yilmaz, "Fuzzy DEMATEL method to evaluate the dimensions of marketing resources: an application in SMEs," Journal of Business Economics and Management, vol. 17, no. 3, pp. 347-364, 2016.

[128] Ö. Kabak, F. Ülengin, B. Çekyay, Ş. Önsel, and Ö. Özaydın, "Critical success factors for the iron and steel industry in Turkey: A fuzzy DEMATEL approach," International Journal of Fuzzy Systems, vol. 18, no. 3, pp. 523-536, 2016.

[129] S. Luthra, K. Govindan, R. K. Kharb, and S. K. Mangla, "Evaluating the enablers in solar power developments in the current scenario using fuzzy DEMATEL: an Indian perspective," Renewable \& Sustainable Energy Reviews, vol. 63, pp. 379397, 2016.
[130] W. W. Wu and Y. T. Lee, "Developing global managers' competencies using the fuzzy DEMATEL method," Expert Systems with Applications, vol. 32, no. 2, pp. 499-507, 2007.

[131] J. J. H. Liou, L. Yen, and G.-H. Tzeng, "Building an effective safety management system for airlines," Journal of Air Transport Management, vol. 14, no. 1, pp. 20-26, 2008.

[132] M.-L. Tseng, "Using the extension of DEMATEL to integrate hotel service quality perceptions into a cause-effect model in uncertainty," Expert Systems with Applications, vol. 36, no. 5, pp. 9015-9023, 2009.

[133] M.-L. Tseng and Y. H. Lin, "Application of fuzzy DEMATEL to develop a cause and effect model of municipal solid waste management in Metro Manila," Environmental Modeling \& Assessment, vol. 158, no. 1-4, pp. 519-533, 2009.

[134] B. Chang, C. Chang, and C. Wu, "Fuzzy DEMATEL method for developing supplier selection criteria," Expert Systems with Applications, vol. 38, no. 3, pp. 1850-1858, 2011.

[135] K.-H. Chang and C.-H. Cheng, "Evaluating the risk of failure using the fuzzy OWA and DEMATEL method," Journal of Intelligent Manufacturing, vol. 22, no. 2, pp. 113-129, 2011.

[136] Q. Zhou, W. Huang, and Y. Zhang, "Identifying critical success factors in emergency management using a fuzzy DEMATEL method," Safety Science, vol. 49, no. 2, pp. 243-252, 2011.

[137] M.-L. Tseng, Y.-H. Chen, and Y. Geng, "Integrated model of hot spring service quality perceptions under uncertainty," Applied Soft Computing, vol. 12, no. 8, pp. 2352-2361, 2012.

[138] M.-L. Tseng, "An assessment of cause and effect decisionmaking model for firm environmental knowledge management capacities in uncertainty," Environmental Modeling \& Assessment, vol. 161, no. 1-4, pp. 549-564, 2010.

[139] W.-W. Wu, "Segmenting critical factors for successful knowledge management implementation using the fuzzy DEMATEL method," Applied Soft Computing, vol. 12, no. 1, pp. 527-535, 2012.

[140] R. J. Lin, "Using fuzzy DEMATEL to evaluate the green supply chain management practices," Journal of Cleaner Production, vol. 40, pp. 32-39, 2013.

[141] S. K. Patil and R. Kant, "A fuzzy DEMATEL method to identify critical success factors of knowledge management adoption in supply chain," Journal of Information and Knowledge Management, vol. 12, no. 3, Article ID 1350019, 2013.

[142] S. Rouhani, A. Ashrafi, and S. Afshari, "Segmenting critical success factors for ERP implementation using an integrated fuzzy AHP and fuzzy DEMATEL approach," World Applied Sciences Journal, vol. 22, no. 8, pp. 1066-1079, 2013.

[143] L. Wu, Q. Zhang, L. Shan, and Z. Chen, "Identifying critical factors influencing the use of additives by food enterprises in China," Food Control, vol. 31, no. 2, pp. 425-432, 2013.

[144] S. Zhou, J. Sun, K.-P. Li, and X. Yang, "Development of a root cause degree procedure for measuring intersection safety factors," Safety Science, vol. 51, no. 1, pp. 257-266, 2013.

[145] Y. Dou, Q. Zhu, and J. Sarkis, "Integrating strategic carbon management into formal evaluation of environmental supplier development programs," Business Strategy and the Environment, vol. 24, no. 8, pp. 873-891, 2015.

[146] K. Govindan, D. Kannan, and K. M. Shankar, "Evaluating the drivers of corporate social responsibility in the mining industry with multi-criteria approach: a multi-stakeholder perspective," Journal of Cleaner Production, vol. 84, no. 1, pp. 214-232, 2014.

[147] S. Routroy and C. V. Sunil Kumar, "Analyzing supplier development program enablers using fuzzy DEMATEL," Measuring Business Excellence, vol. 18, no. 4, pp. 1-26, 2014. 
[148] M. Tyagi, P. Kumar, and D. Kumar, "Assessment of critical enablers for flexible supply chain performance measurement system using fuzzy DEMATEL approach," Global Journal of Flexible Systems Management, vol. 16, no. 2, pp. 115-132, 2015.

[149] K.-J. Wu, C.-J. Liao, M.-L. Tseng, and A. S. F. Chiu, "Exploring decisive factors in green supply chain practices under uncertainty," International Journal of Production Economics, vol. 159, pp. 147-157, 2015.

[150] A. K. Sangaiah, P. R. Subramaniam, and X. Zheng, "A combined fuzzy DEMATEL and fuzzy TOPSIS approach for evaluating GSD project outcome factors," Neural Computing and Applications, vol. 26, no. 5, pp. 1025-1040, 2015.

[151] R. K. Malviya and R. Kant, "Hybrid decision making approach to predict and measure the success possibility of green supply chain management implementation," Journal of Cleaner Production, vol. 135, pp. 387-409, 2016.

[152] S. K. Patil and R. Kant, "A hybrid approach based on fuzzy DEMATEL and FMCDM to predict success of knowledge management adoption in supply chain," Applied Soft Computing, vol. 18, pp. 126-135, 2014.

[153] A. K. Sangaiah, J. Gopal, A. Basu, and P. R. Subramaniam, "An integrated fuzzy DEMATEL, TOPSIS, and ELECTRE approach for evaluating knowledge transfer effectiveness with reference to GSD project outcome," Neural Computing and Applications, vol. 28, no. 1, pp. 111-123, 2017.

[154] E. A. Bakeshlou, A. A. Khamseh, M. A. G. Asl, J. Sadeghi, and M. Abbaszadeh, "Evaluating a green supplier selection problem using a hybrid MODM algorithm," Journal of Intelligent Manufacturing, vol. 28, no. 4, pp. 913-927, 2017.

[155] J. Jassbi, F. Mohamadnejad, and H. Nasrollahzadeh, "A fuzzy DEMATEL framework for modeling cause and effect relationships of strategy map," Expert Systems with Applications, vol. 38, no. 5, pp. 5967-5973, 2011.

[156] Y.-C. Lee, M.-L. Li, T.-M. Yen, and T.-H. Huang, "Analysis of fuzzy decision making trial and evaluation laboratory on technology acceptance model," Expert Systems with Applications, vol. 38, no. 12, pp. 14407-14416, 2011.

[157] C. Valmohammadi and J. Sofiyabadi, "Modeling cause and effect relationships of strategy map using fuzzy DEMATEL and fourth generation of balanced scorecard," Benchmarking, vol. 22, no. 6, pp. 1175-1191, 2015.

[158] M. Younesi and E. Roghanian, "A framework for sustainable product design: a hybrid fuzzy approach based on quality function deployment for environment," Journal of Cleaner Production, vol. 108, pp. 385-394, 2015.

[159] C. J. Lin and W. W. Wu, "A causal analytical method for group decision-making under fuzzy environment," Expert Systems with Applications, vol. 34, no. 1, pp. 205-213, 2008.

[160] R. Fekri, A. Aliahmadi, and M. Fathian, "Identifying the cause and effect factors of agile NPD process with fuzzy DEMATEL method: The case of Iranian companies," Journal of Intelligent Manufacturing, vol. 20, no. 6, pp. 637-648, 2009.

[161] D. J.-F. Jeng and G.-H. Tzeng, "Social influence on the use of clinical decision support systems: revisiting the unified theory of acceptance and use of technology by the fuzzy DEMATEL technique," Computers \& Industrial Engineering, vol. 62, no. 3, pp. 819-828, 2012.

[162] Y.-C. Chou, C.-C. Sun, and H.-Y. Yen, "Evaluating the criteria for human resource for science and technology (HRST) based on an integrated fuzzy AHP and fuzzy DEMATEL approach," Applied Soft Computing, vol. 12, no. 1, pp. 64-71, 2012.
[163] M.-A. Afsharkazemi, J. Manouchehri, M. Salarifar, and A. A. Nasiripour, "Key factors affecting the hospital performance: a qualitative study using fuzzy logic," Quality \& Quantity, vol. 47, no. 6, pp. 3559-3573, 2013.

[164] J. Ren and B. K. Sovacool, "Quantifying, measuring, and strategizing energy security: determining the most meaningful dimensions and metrics," Energy, vol. 76, pp. 838-849, 2014.

[165] E. Akyuz and E. Celik, "A fuzzy DEMATEL method to evaluate critical operational hazards during gas freeing process in crude oil tankers," Journal of Loss Prevention in the Process Industries, vol. 38, pp. 243-253, 2015.

[166] C.-C. Tsao and W.-W. Wu, "Evaluation of design conditions for compound special-core drilling composite materials using the fuzzy DEMATEL method," International Journal of Computer Integrated Manufacturing, vol. 27, no. 11, pp. 979-985, 2014.

[167] L.-H. Ho, M.-T. Hsu, and T.-M. Yen, "Identifying core control items of information security management and improvement strategies by applying fuzzy DEMATEL," Information and Computer Security, vol. 23, no. 2, pp. 161-177, 2015.

[168] D. J.-F. Jeng, "Generating a causal model of supply chain collaboration using the fuzzy DEMATEL technique," Computers \& Industrial Engineering, vol. 87, pp. 283-295, 2015.

[169] H.-C. Liu, J.-X. You, Q.-L. Lin, and H. Li, "Risk assessment in system FMEA combining fuzzy weighted average with fuzzy decision-making trial and evaluation laboratory," International Journal of Computer Integrated Manufacturing, vol. 28, no. 7, pp. 701-714, 2015.

[170] F. Panaihfar, C. Heavey, and P. J. Byrne, “Developing retailer selection factors for collaborative planning, forecasting and replenishment," Industrial Management \& Data Systems, vol. 115, no. 7, pp. 1292-1324, 2015.

[171] C.-Y. Hsu, K.-T. Chen, and G.-H. Tzeng, "FMCDM with fuzzy DEMATEL approach for customers' choice behavior model," International Journal of Fuzzy Systems, vol. 9, no. 4, pp. 236-246, 2007.

[172] S. Cebi, "A quality evaluation model for the design quality of online shopping websites," Electronic Commerce Research and Applications, vol. 12, no. 2, pp. 124-135, 2013.

[173] L. Gigović, D. Pamučar, D. Lukić, and S. Marković, "GISFuzzy DEMATEL MCDA model for the evaluation of the sites for ecotourism development: a case study of 'Dunavski ključ' region, Serbia," Land Use Policy, vol. 58, pp. 348-365, 2016.

[174] J. S. Jeong, L. García-Moruno, J. Hernández-Blanco, and A. Sánchez-Ríos, "Planning of rural housings in reservoir areas under (mass) tourism based on a fuzzy DEMATEL-GIS/MCDA hybrid and participatory method for Alange, Spain," Habitat International, vol. 57, pp. 143-153, 2016.

[175] M. J. Rahimdel and R. Bagherpour, "Haulage system selection for open pit mines using fuzzy MCDM and the view on energy saving," Neural Computing and Applications, pp. 1-13, 2016.

[176] D. Dalalah, M. Hayajneh, and F. Batieha, "A fuzzy multi-criteria decision making model for supplier selection," Expert Systems with Applications, vol. 38, no. 7, pp. 8384-8391, 2011.

[177] M. Hiete, M. Merz, T. Comes, and F. Schultmann, “Trapezoidal fuzzy DEMATEL method to analyze and correct for relations between variables in a composite indicator for disaster resilience," OR Spectrum, vol. 34, no. 4, pp. 971-995, 2012.

[178] C.-H. Wang and J.-N. Chen, "Using quality function deployment for collaborative product design and optimal selection of module mix," Computers \& Industrial Engineering, vol. 63, no. 4, pp. 1030-1037, 2012. 
[179] C.-H. Wang, "Using quality function deployment to conduct vendor assessment and supplier recommendation for businessintelligence systems," Computers \& Industrial Engineering, vol. 84, pp. 24-31, 2015.

[180] A. Baykasoǧlu, V. Kaplanoglu, Z. D. U. Durmuşoglu, and C. Şahin, "Integrating fuzzy DEMATEL and fuzzy hierarchical TOPSIS methods for truck selection," Expert Systems with Applications, vol. 40, no. 3, pp. 899-907, 2013.

[181] C. H. Wang and H. S. Wu, "A novel framework to evaluate programmable logic controllers: a fuzzy MCDM perspective," Journal of Intelligent Manufacturing, vol. 27, no. 2, pp. 315-324, 2016.

[182] A. Fetanat and E. Khorasaninejad, "A novel hybrid MCDM approach for offshore wind farm site selection: a case study of Iran," Ocean \& Coastal Management, vol. 109, pp. 17-28, 2015.

[183] S.-K. Hu, M.-T. Lu, and G.-H. Tzeng, "Improving mobile commerce adoption using a new hybrid fuzzy MADM model," International Journal of Fuzzy Systems, vol. 17, no. 3, pp. 399-413, 2015.

[184] G. A. Keskin, "Using integrated fuzzy DEMATEL and fuzzy C: means algorithm for supplier evaluation and selection," International Journal of Production Research, vol. 53, no. 12, pp. 3586-3602, 2015.

[185] D. Pamučar and G. Ćirović, "The selection of transport and handling resources in logistics centers using Multi-Attributive Border Approximation area Comparison (MABAC)," Expert Systems with Applications, vol. 42, no. 6, pp. 3016-3028, 2015.

[186] H. Taşkin, Ü. A. Kahraman, and C. Kubat, "Evaluation of the hospital service in Turkey using fuzzy decision making approach," Journal of Intelligent Manufacturing, 2015.

[187] X. Fu, Q. Zhu, and J. Sarkis, "Evaluating green supplier development programs at a telecommunications systems provider," International Journal of Production Economics, vol. 140, no. 1, pp. 357-367, 2012.

[188] Y. Dou and J. Sarkis, "A multiple stakeholder perspective on barriers to implementing China RoHS regulations," Resources, Conservation \& Recycling, vol. 81, pp. 92-104, 2013.

[189] Q. Zhu, J. Sarkis, and K.-H. Lai, "Supply chain-based barriers for truck-engine remanufacturing in China," Transportation Research Part E: Logistics and Transportation Review, vol. 68, pp. 103-117, 2014.

[190] R. Rajesh and V. Ravi, "Modeling enablers of supply chain risk mitigation in electronic supply chains: a Grey-DEMATEL approach," Computers \& Industrial Engineering, vol. 87, pp. 126139, 2015.

[191] J. Shao, M. Taisch, and M. Ortega-Mier, "A grey-decisionmaking trial and evaluation laboratory (DEMATEL) analysis on the barriers between environmentally friendly products and consumers: practitioners' viewpoints on the European automobile industry," Journal of Cleaner Production, vol. 112, pp. 3185-3194, 2016.

[192] K. Govindan, R. Khodaverdi, and A. Vafadarnikjoo, "A grey DEMATEL approach to develop third-party logistics provider selection criteria," Industrial Management \& Data Systems, vol. 116, no. 4, pp. 690-722, 2016.

[193] X. Xia, K. Govindan, and Q. Zhu, "Analyzing internal barriers for automotive parts remanufacturers in China using greyDEMATEL approach," Journal of Cleaner Production, vol. 87, no. 1, pp. 811-825, 2015.

[194] C. Bai and J. Sarkis, "A grey-based DEMATEL model for evaluating business process management critical success factors,"
International Journal of Production Economics, vol. 146, no. 1, pp. 281-292, 2013.

[195] H. Liang, J. Ren, Z. Gao et al., "Identification of critical success factors for sustainable development of biofuel industry in China based on grey decision-making trial and evaluation laboratory (DEMATEL)," Journal of Cleaner Production, vol. 131, pp. 500508, 2016.

[196] M.-L. Tseng, "A causal and effect decision making model of service quality expectation using grey-fuzzy DEMATEL approach," Expert Systems with Applications, vol. 36, no. 4, pp. 7738-7748, 2009.

[197] C.-M. Su, D.-J. Horng, M.-L. Tseng, A. S. F. Chiu, K.-J. Wu, and H.-P. Chen, "Improving sustainable supply chain management using a novel hierarchical grey-DEMATEL approach," Journal of Cleaner Production, vol. 134, pp. 469-481, 2016.

[198] T. Ozcan and F. Tuysuz, "Modified grey relational analysis integrated with grey dematel approach for the performance evaluation of retail stores," International Journal of Information Technology \& Decision Making, vol. 15, no. 2, pp. 353-386, 2016.

[199] K. Jenab, A. Sarfaraz, P. D. Weinsier, A. Moeini, and A. M. A. AlAhmari, "I-DEMATEL method for integrated manufacturing technology selection," Journal of Manufacturing Technology Management, vol. 26, no. 3, pp. 349-363, 2015.

[200] L. Abdullah and N. Zulkifli, "Integration of fuzzy AHP and interval type-2 fuzzy DEMATEL: an application to human resource management," Expert Systems with Applications, vol. 42, no. 9, pp. 4397-4409, 2015.

[201] A. V. Nikjoo and M. Saeedpoor, "An intuitionistic fuzzy DEMATEL methodology for prioritising the components of SWOT matrix in the Iranian insurance industry," International Journal of Operational Research, vol. 20, no. 4, pp. 439-452, 2014.

[202] K. Govindan, R. Khodaverdi, and A. Vafadarnikjoo, "Intuitionistic fuzzy based DEMATEL method for developing green practices and performances in a green supply chain," Expert Systems with Applications, vol. 42, no. 20, pp. 7207-7220, 2015.

[203] Z. P. Fan, W. Suo, and B. Feng, "Identifying risk factors of IT outsourcing using interdependent information: an extended DEMATEL method," Expert Systems with Applications, vol. 39, no. 3, pp. 3832-3840, 2012.

[204] H. Liu, J. X. You, Ch. Lu, and Y. Z. Chen, "Evaluating health-care waste treatment technologies using a hybrid multi-criteria decision making model," Renewable \& Sustainable Energy Reviews, vol. 41, pp. 932-942, 2015.

[205] W.-L. Suo, B. Feng, and Z.-P. Fan, "Extension of the DEMATEL method in an uncertain linguistic environment," Soft Computing, vol. 16, no. 3, pp. 471-483, 2012.

[206] Y. Li, Y. Hu, X. Zhang, Y. Deng, and S. Mahadevan, "An evidential DEMATEL method to identify critical success factors in emergency management," Applied Soft Computing, vol. 22, pp. 504-510, 2014.

[207] K.-H. Chang and C.-H. Cheng, "A risk assessment methodology using intuitionistic fuzzy set in FMEA," International Journal of Systems Science, vol. 41, no. 12, pp. 1457-1471, 2010.

[208] K.-H. Chang, "A more general risk assessment methodology using a soft set-based ranking technique," Soft Computing, vol. 18, no. 1, pp. 169-183, 2014.

[209] X. Geng and X. Chu, "A new importance-performance analysis approach for customer satisfaction evaluation supporting PSS design," Expert Systems with Applications, vol. 39, no. 1, pp. 14921502, 2012. 
[210] S.-M. Wu, H.-C. Liu, and L.-E. Wang, "Hesitant fuzzy integrated MCDM approach for quality function deployment: a case study in electric vehicle," International Journal of Production Research, vol. 55, no. 15, pp. 4436-4449, 2017.

[211] W.-W. Wu, "Choosing knowledge management strategies by using a combined ANP and DEMATEL approach," Expert Systems with Applications, vol. 35, no. 3, pp. 828-835, 2008.

[212] G. Büyüközkan and G. Çifçi, "A novel hybrid MCDM approach based on fuzzy DEMATEL, fuzzy ANP and fuzzy TOPSIS to evaluate green suppliers," Expert Systems with Applications, vol. 39, no. 3, pp. 3000-3011, 2012.

[213] W.-H. Tsai and W.-C. Chou, "Selecting management systems for sustainable development in SMEs: a novel hybrid model based on DEMATEL, ANP, and ZOGP," Expert Systems with Applications, vol. 36, no. 2, pp. 1444-1458, 2009.

[214] L. A. Zadeh, "Fuzzy sets," Information and Control, vol. 8, no. 3, pp. 338-353, 1965.

[215] S. Opricovic and G.-H. Tzeng, "Defuzzification within a multicriteria decision model," International Journal of Uncertainty, Fuzziness and Knowledge-Based Systems, vol. 11, no. 5, pp. 635652, 2003.

[216] J. Gopal, A. K. Sangaiah, A. Basu, and X. Z. Gao, "Integration of fuzzy DEMATEL and FMCDM approach for evaluating knowledge transfer effectiveness with reference to GSD project outcome," International Journal of Machine Learning and Cybernetics, pp. 1-17, 2015.

[217] A. K. Sangaiah, X. Z. Gao, M. Ramachandran, and X. Zheng, "A fuzzy DEMATEL approach based on intuitionistic fuzzy information for evaluating knowledge transfer effectiveness in GSD projects," International Journal of Innovative Computing and Applications, vol. 6, no. 3-4, pp. 203-215, 2015.

[218] C.-W. Li and G.-H. Tzeng, "Identification of a threshold value for the DEMATEL method using the maximum mean deentropy algorithm to find critical services provided by a semiconductor intellectual property mall," Expert Systems with Applications, vol. 36, no. 6, pp. 9891-9898, 2009. 


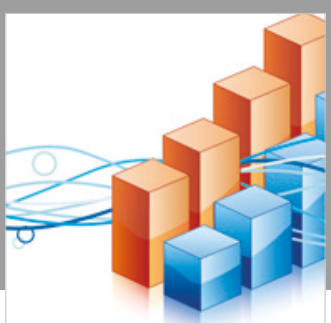

Advances in

Operations Research

\section{-n-m}
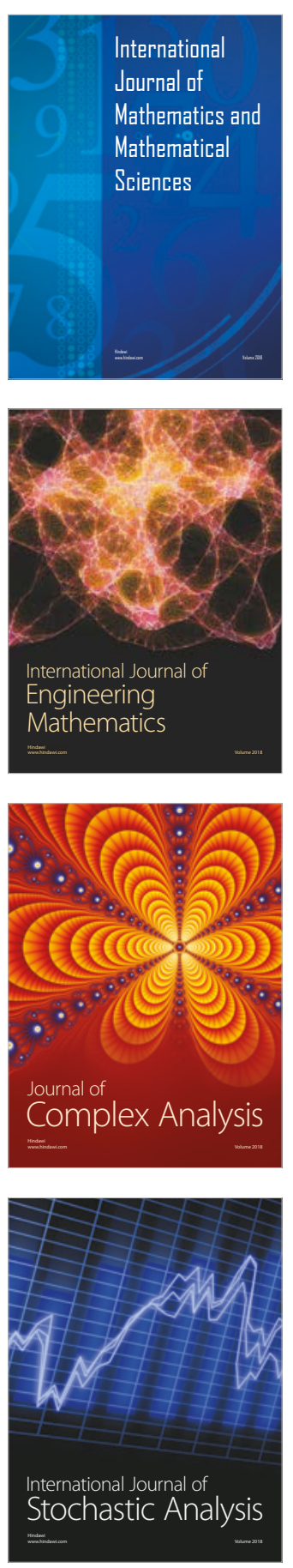
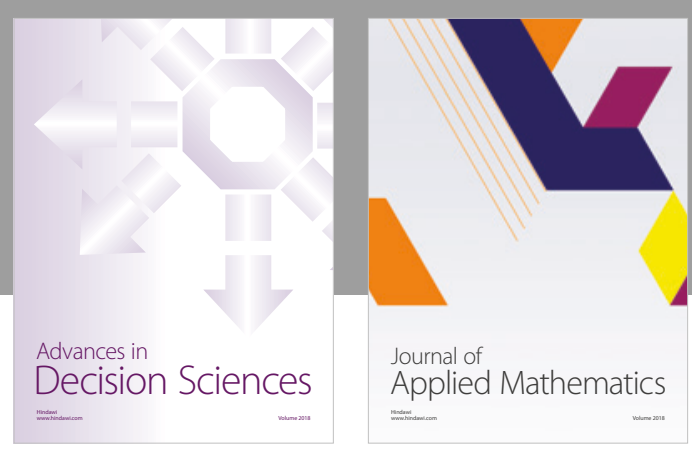

Journal of

Applied Mathematics
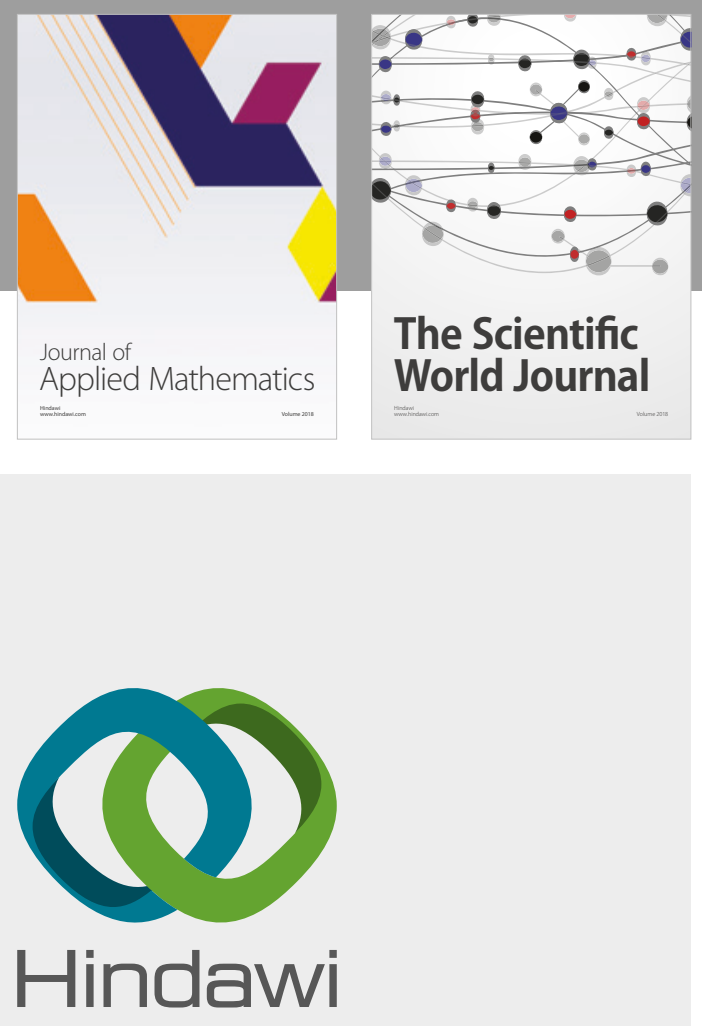

Submit your manuscripts at

www.hindawi.com

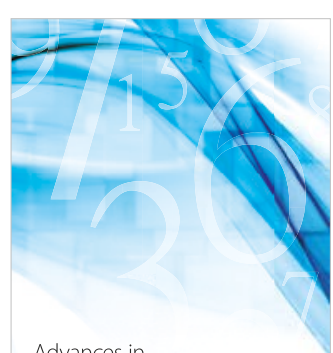

Advances in
Numerical Analysis
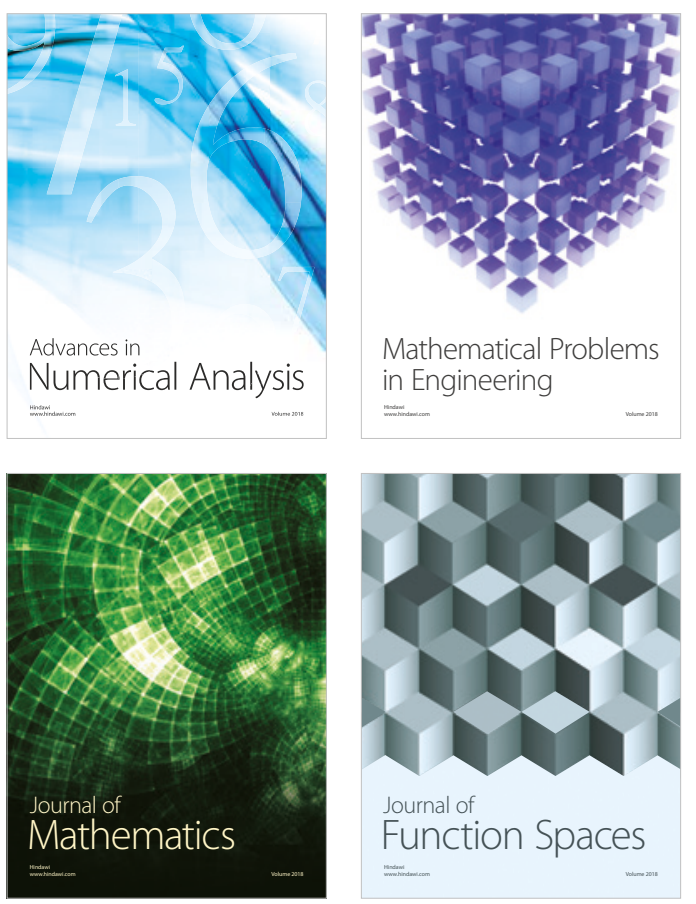

Mathematical Problems in Engineering

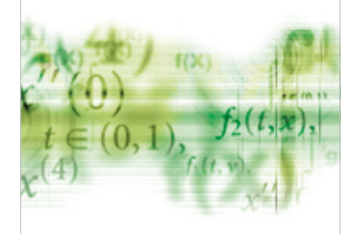

International Journal of

Differential Equations

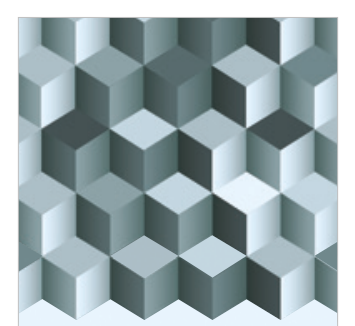

Journal of

Function Spaces

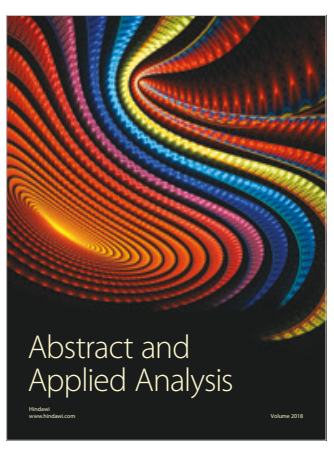

The Scientific

World Journal

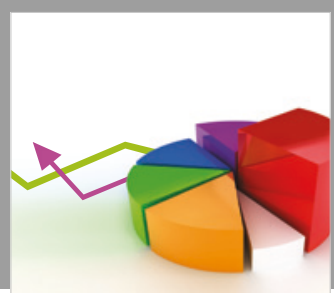

Journal of

Probability and Statistics
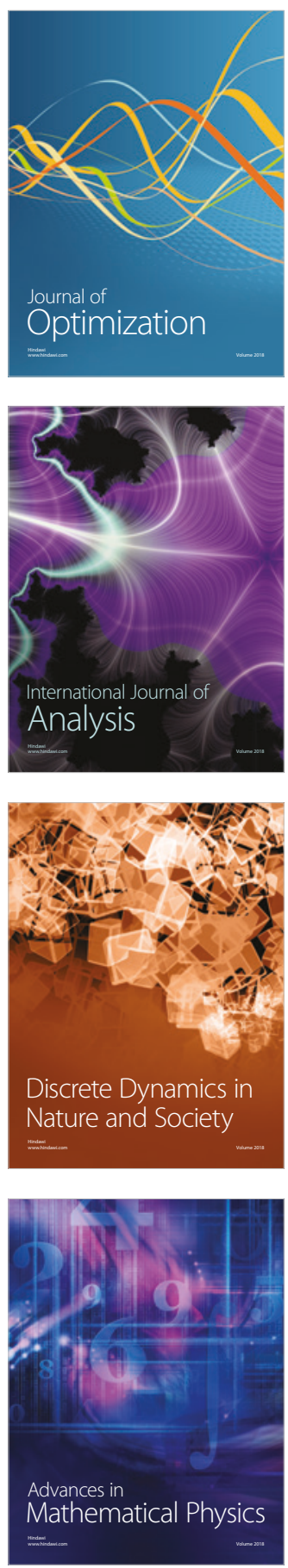